\title{
6. UNDERWAY GEOPHYSICAL MEASUREMENTS: GLOMAR CHALLENGER LEG 71 ${ }^{1}$
}

\author{
William J. Ludwig² and Philip D. Rabinowitz, Lamont-Doherty Geological Observatory of Columbia University, \\ Palisades, New York
}

Bathymetric, magnetic, and single-channel seismic reflection data were acquired during Glomar Challenger Leg 71. The ship departed Valparaiso, Chile on January 3, 1979 and proceeded to Punta Arenas, Chile, with a partial scientific and technical staff. The ship arrived at Punta Arenas on January 10, 1980, embarked 11 scientists and 5 Scripps personnel, and departed for Site 511 the same day. The ship's track from Valparaiso to arrival at Santos, Brazil, on February 21 is shown in Figures 1 and 2. Dates and times for the first navigational fix of the day along the ship's track where data were obtained and drill site locations are indicated. Table 1 lists the positioning information acquired underway by the satellite navigation system and used to plot the ship's track (Talwani et al., 1966). Also listed in Table 1 are the regional magnetic field values, computed at each navigation point according to the reference field of Fabiano and Peddie (1969) and used to determine the magnetic anomaly profiles in Figures 3 and 4.

Magnetic anomalies, plotted normal to the Challenger track and L-DGO ship's tracks in the vicinity of Sites 513 and 514, are shown in Figure 3. In this diagram, the zero level for the magnetic anomalies has been arbitrarily adjusted to avoid confusion and also to clarify the shorter wavelength positive-negative anomaly trends. The total track coverage allows us to identify some key seafloor spreading anomalies. The anomalies are identified according to the numbering system of Heirtzler et al. (1968) and LaBrecque et al. (1977). The base of the sedimentary section cored at Site 513 is estimated to be approximately $36.5 \mathrm{~m} . y$. old-i.e., near the Oligocene/ Eocene boundary ( $37 \mathrm{Ma}$ ). Thus a basement age of 36.5 m.y. would correspond to a position midway between Anomalies 13 and 15 (basal Oligocene), which is exactly the crustal age predicted by the magnetic anomalies.

Figure 4 shows bathymetric and magnetic anomaly profiles plotted as functions of time, distance, latitude, and longitude. The data processing procedure, including program listings, is given in Talwani (1969). The vertical scales show depth (D) in uncorrected fathoms (assuming a sound speed of $800 \mathrm{fms} / \mathrm{s}$ and total intensity

\footnotetext{
${ }^{1}$ Ludwig, W. J., Krasheninnikov, V. A., et al., Init. Repts, DSDP, 71: Washington (U.S, Govt. Printing Office).

2 Present address: Gulf Oil Exploration and Production Co., P.O. Box 36506, Houston,
al 77236.
}

magnetic $[\mathrm{M}]$ anomaly values in gammas). On the lowermost scale at the bottom of the figure, distances are shown at intervals of $\mathbf{2 0 0}$ miles. In addition, tick marks above the distance scale indicate the distance at which any change in course or speed occurred. The corresponding course and speed between changes and the coordinates at the points of change are noted above the distance scale listings. At the top of the figure, from top to bottom, are time in days, time in hours, latitude in degrees, and longitude in degrees.

Seismic reflection profile records obtained along the ship's track (Fig. 1 and 2) are given in Figure 5. These data were recorded analog during 10-s sweeps of an EDO chart recorder, using a $20-\mathrm{in}^{3}$. and a $40-\mathrm{in}^{3}$. Bolt airgun fired simultaneously as the sound source and a Scripps-designed hydrophone array. Depths are labeled on the sides of the records in two-way reflection time (1 $\mathrm{s}$ water $=400 \mathrm{fms}$ or $732 \mathrm{~m} ; 1 \mathrm{~s}$ sediments $=1000 \mathrm{~m}$, assuming the velocity in the sediments to be $2000 \mathrm{~m} / \mathrm{s}$ ). Times and dates are shown on the records to key into the navigation plots (Fig. 1 and 2) and listing (Table 1).

\section{ACKNOWLEDGMENTS}

Appreciation is expressed to Gerald Bode and his shipboard technical group for obtaining the underway geophysical data during Leg 71. Preparation of this report was aided by Grant OCE-77-25992 from the Oceanography Section of the National Science Foundation.

\section{REFERENCES}

Fabiano, E. G., and Peddie, N. U., 1969. Grid values of total magnetic intensity I.G.R.F., 1965. U.S. ESSA Tech. Rept., 38:55.

Heezen, B. C., and Tharp, M., 1978. General Bathymetric Chart of the Oceans 5th Edition, Sheet 5.12, Scale 1:10,000,000: Ottawa (Canadian Hydrographic Service).

Heirtzler, J. R., Dickson, G. O., Herron, E. M., Pitman, W. C., III, and Le Pichon, S., 1968. Marine magnetic anomalies, geomagnetic field reversals and motions of the ocean floor and continents. $J$. Geophys. Res., 73:2119-2136.

LaBrecque, J. L., Kent, D. V., and Cande, S. C., 1977. Revised magnetic polarity time scale for the Late Cretaceous and Cenozoic. Geology, 5 (No. 6):330-335.

LaBrecque, J. L., and Rabinowitz, 1981. General Bathymetric Chart of the Oceans, 5th Edition, Sheet 5.16, Scale 1:10,000,000: Ottawa (Canadian Hydrographic Service).

Talwani, M., 1969. A computer system for the reduction, storage, and display of underway data acquired at sea. Lamont-Doherty Geological Observatory of Columbia University Tech. Rept. I, CU-169 N00014-67-A-0108-0004:348.

Talwani, M., Dorman, J., Worzel, J. L., and Bryan, G. M., 1966. Navigation at sea by satellite. J. Geophys. Res., 71:5891-5902. 


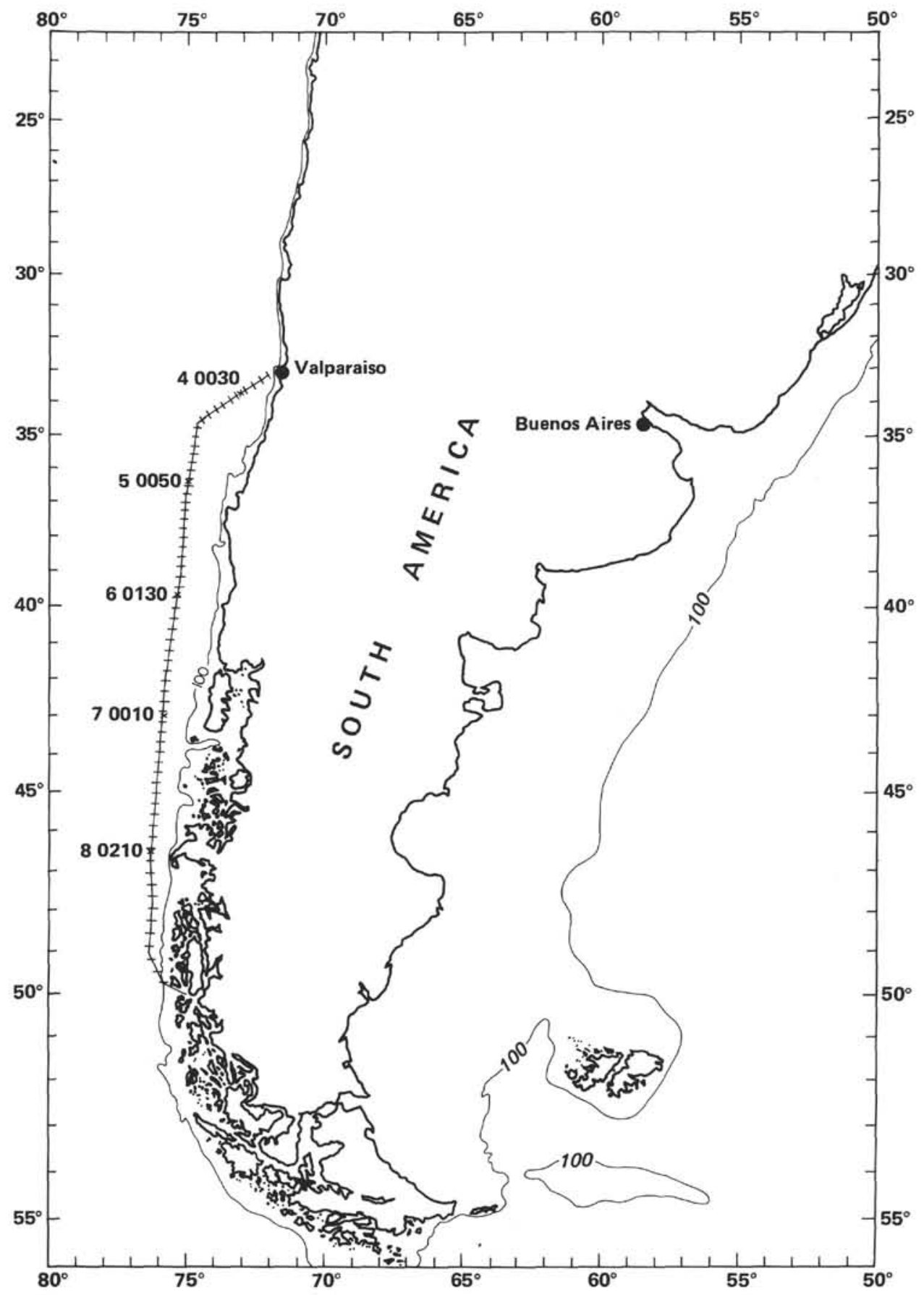

Figure 1. Track chart for transit Leg 71 of Glomar Challenger from Valparaiso, Chile, to Punta Arenas, Chile. Numbers indicate date and time of first navigation fix every day; ticks give time every two hours. 


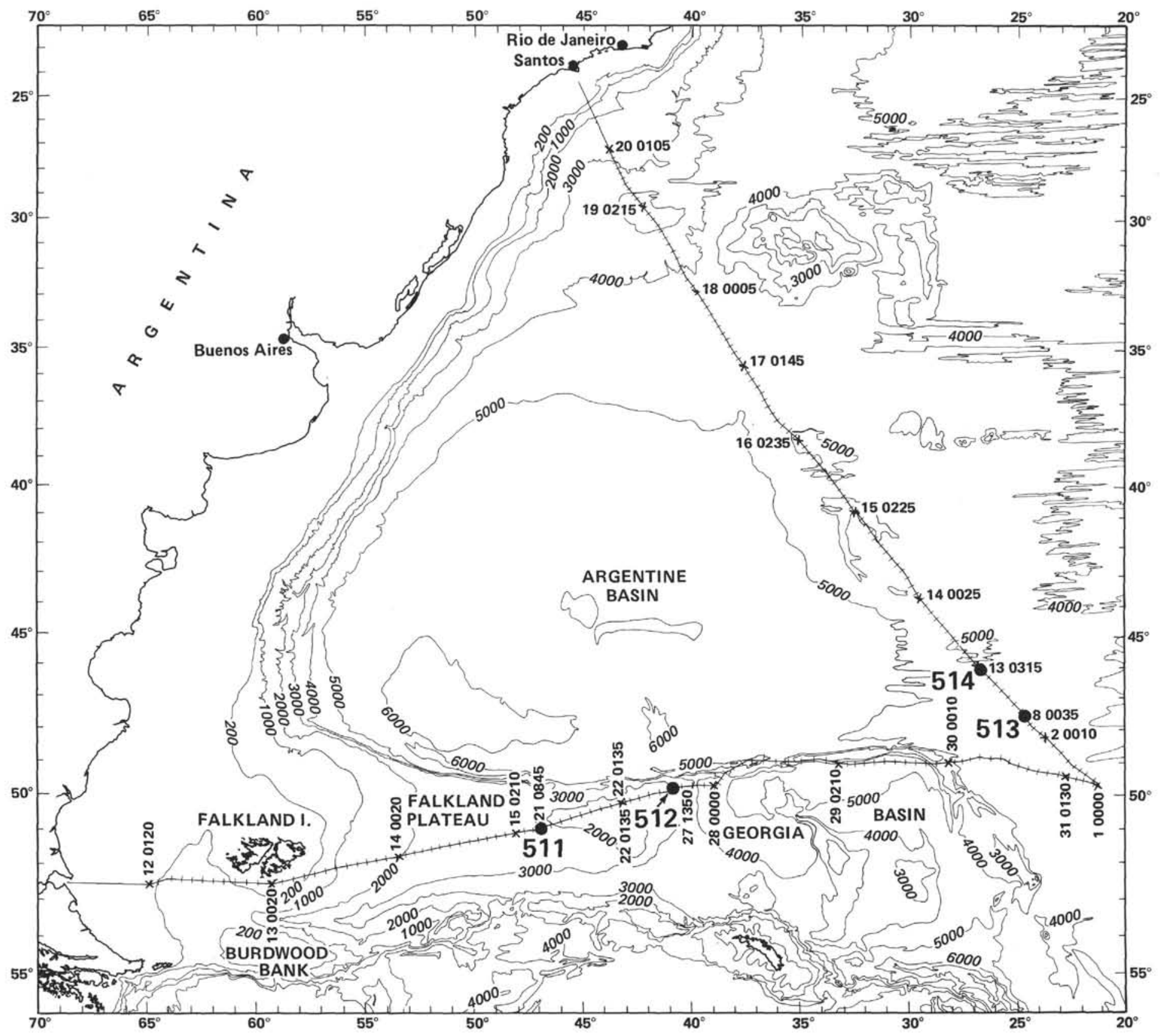

Figure 2. Track chart for Leg 71 of Glomar Challenger from Punta Arenas, Chile, to Santos, Brazil. Numbers indicate date and time of first navigation fix every day; ticks give time every two hours. Generalized bathymetry in meters north and south of $45^{\circ} \mathrm{S}$ after Heezen and Tharp (1978) and LaBrecque and Rabinowitz (1981), respectively. 
Table 1. Positioning information and magnetic field values, Leg 71 of Glomar Challenger.

\begin{tabular}{|c|c|c|}
\hline $\begin{array}{c}\text { Day/Month } \\
\text { Year }\end{array}$ & $\begin{array}{l}\text { Time } \\
\text { Zone }\end{array}$ & Time \\
\hline $\begin{array}{l}3 / 1 / 80 \\
31 / 80\end{array}$ & 0.0 & 1530 \\
\hline $\begin{array}{l}\begin{array}{l}3 / 1 / 180 \\
3 / 1 / 80\end{array} \\
3\end{array}$ & $\begin{array}{l}0.0 \\
0.0\end{array}$ & 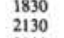 \\
\hline $4 / 1 / 80$ & 0.0 & 0030 \\
\hline $4 / 1 / 80$ & 0.0 & 0200 \\
\hline $4 / 1 / 80$ & 0.0 & $\begin{array}{l}0430 \\
0530\end{array}$ \\
\hline $\begin{array}{l}4 / 1 / 180 \\
4 / 180\end{array}$ & $\begin{array}{l}0.0 \\
0.0\end{array}$ & $\begin{array}{l}05380 \\
0550\end{array}$ \\
\hline $4 / 1 / 80$ & 0.0 & 0600 \\
\hline $4 / 1 / 80$ & 0.0 & 0900 \\
\hline $4 / 1 / 80$ & 0.0 & 1110 \\
\hline $4 / 1 / 80$ & 0.0 & 1120 \\
\hline $4 / 1 / 80$ & 0.0 & 1310 \\
\hline $4 / 1 / 80$ & 0.0 & $\begin{array}{l}1450 \\
170\end{array}$ \\
\hline $4 / 1 / 80$ & 0.0 & 1750 \\
\hline 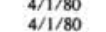 & $\begin{array}{l}0.0 \\
0.0\end{array}$ & 2 \\
\hline $\begin{array}{l}4 / 1 / 80 \\
4 / 1 / 80\end{array}$ & 0.0 & $\begin{array}{l}2030 \\
2100\end{array}$ \\
\hline $\begin{array}{l}4 / 1 / 80 \\
4\end{array}$ & $\begin{array}{l}0.0 \\
0.0\end{array}$ & $\begin{array}{l}\begin{array}{l}2100 \\
2210\end{array} \\
\text { 2. }\end{array}$ \\
\hline $4 / 1 / 80$ & 0.0 & 2320 \\
\hline $5 / 1 / 80$ & 0.0 & 0220 \\
\hline & 0.0 & 0230 \\
\hline $5 / 1 / 80$ & 0.0 & $\begin{array}{l}0520 \\
0730 \\
0730\end{array}$ \\
\hline $\begin{array}{l}5 / 1 / 80 \\
5 / 1 / 80\end{array}$ & 0.0 & $\begin{array}{l}0730 \\
0740\end{array}$ \\
\hline S/1/80 & 0.0 & $\begin{array}{l}0800 \\
0800\end{array}$ \\
\hline $5 / 1 / 80$ & 0.0 & 0810 \\
\hline $5 / 1 / 80$ & 0.0 & 0920 \\
\hline $5 / 1 / 80$ & 0.0 & 1040 \\
\hline $5 / 1 / 80$ & 0.0 & 1340 \\
\hline $5 / 1 / 80$ & 0.0 & 1640 \\
\hline $5 / 1 / 80$ & 0.0 & 1940 \\
\hline $\begin{array}{l}5 / 1 / 80 \\
5 / 1 / 80\end{array}$ & $\begin{array}{l}0.0 \\
0.0\end{array}$ & $\begin{array}{l}22200 \\
2230\end{array}$ \\
\hline $\begin{array}{l}5 / 1 / 80 \\
6 / 1 / 80\end{array}$ & $\begin{array}{l}0.0 \\
0.0\end{array}$ & 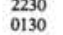 \\
\hline $6 / 1 / 80$ & 0.0 & $\begin{array}{l}{ }_{0}^{1130} 0 \\
0430\end{array}$ \\
\hline $6 / 1 / 80$ & 0.0 & 0730 \\
\hline $6 / 1 / 80$ & 0.0 & 1030 \\
\hline $6 / 1 / 80$ & 0.0 & 1330 \\
\hline $6 / 1 / 80$ & 0.0 & 1450 \\
\hline $\begin{array}{l}6 / 1 / 80 \\
6 / 1 / 80\end{array}$ & $\begin{array}{l}0.0 \\
0.0\end{array}$ & $\begin{array}{l}1500 \\
1510\end{array}$ \\
\hline $\begin{array}{l}6 / 1 / 80 \\
6 / 1 / 80\end{array}$ & $\begin{array}{l}0.0 \\
0.0\end{array}$ & $\begin{array}{l}\begin{array}{l}1510 \\
1810\end{array} \\
180\end{array}$ \\
\hline $6 / 1 / 80$ & 0.0 & $\begin{array}{l}1810 \\
2110\end{array}$ \\
\hline $7 / 1 / 80$ & 0.0 & 0010 \\
\hline $7 / 1 / 80$ & 0.0 & 0310 \\
\hline $7 / 1 / 80$ & 0.0 & 0610 \\
\hline $7 / 1 / 80$ & 0.0 & 0910 \\
\hline $\begin{array}{l}7 / 1 / 80 \\
7 / 1 / 80\end{array}$ & $\begin{array}{l}0.0 \\
0.0\end{array}$ & $\begin{array}{l}1210 \\
1410\end{array}$ \\
\hline $\begin{array}{l}7 / 1 / 80 \\
7 / 1 / 80\end{array}$ & $\begin{array}{l}0.0 \\
0.0\end{array}$ & $\begin{array}{l}1410 \\
1710\end{array}$ \\
\hline $7 / 1 / 80$ & $\begin{array}{l}0.0 \\
0.0\end{array}$ & $\begin{array}{l}1710 \\
2010\end{array}$ \\
\hline $7 / 1 / 80$ & 0.0 & 2310 \\
\hline $8 / 1 / 80$ & 0.0 & 0210 \\
\hline $8 / 1 / 80$ & 0.0 & 0300 \\
\hline $8 / 1 / 80$ & 0.0 & 0600 \\
\hline $8 / 1 / 80$ & 0.0 & $\begin{array}{l}0630 \\
0840 \\
0840\end{array}$ \\
\hline $\begin{array}{l}8 / 1 / 80 \\
8 / 1 / 80\end{array}$ & $\begin{array}{l}0.0 \\
0.0\end{array}$ & $\begin{array}{l}\begin{array}{l}8840 \\
1030\end{array}\end{array}$ \\
\hline $8 / 1 / 80$ & 0.0 & $\begin{array}{l}1130 \\
1130\end{array}$ \\
\hline $8 / 1 / 80$ & 0.0 & 1430 \\
\hline $8 / 1 / 80$ & 0.0 & 1730 \\
\hline $8 / 1 / 80$ & 0.0 & 1850 \\
\hline $8 / 1 / 80$ & 0.0 & 1910 \\
\hline $8 / 1 / 80$ & 0.0 & 2210 \\
\hline $\begin{array}{l}8 / 1 / 80 \\
8 / 1 / 80\end{array}$ & $\begin{array}{l}0.0 \\
0.0\end{array}$ & $\begin{array}{l}2240 \\
2310\end{array}$ \\
\hline $\begin{array}{l}8 / 1 / 80 \\
8 / 1 / 80\end{array}$ & $\begin{array}{l}0.0 \\
0.0\end{array}$ & $\begin{array}{l}2310 \\
2320\end{array}$ \\
\hline $8 / 1 / 80$ & 0.0 & 2330 \\
\hline $9 / 1 / 80$ & 0.0 & 0230 \\
\hline $9 / 1 / 80$ & 0.0 & 0510 \\
\hline $9 / 1 / 80$ & 0.0 & 0520 \\
\hline $\begin{array}{l}9 / 1 / 80 \\
9 / 1 / 80\end{array}$ & $\begin{array}{l}0.0 \\
0.0\end{array}$ & $\begin{array}{l}0750 \\
0800\end{array}$ \\
\hline & $\begin{array}{l}0.0 \\
0.0\end{array}$ & $\begin{array}{l}0800 \\
0850\end{array}$ \\
\hline $9 / 1 / 80$ & $\begin{array}{l}0.0 \\
0.0\end{array}$ & 0940 \\
\hline & 0.0 & 1020 \\
\hline & 0.0 & 1030 \\
\hline $9 / 1 / 80$ & 0.0 & 1040 \\
\hline & 0.0 & $\begin{array}{l}1340 \\
1400\end{array}$ \\
\hline $9 / 1 / 80$ & $\begin{array}{l}0.0 \\
0.0\end{array}$ & $\begin{array}{l}1400 \\
1410\end{array}$ \\
\hline $9 / 1 / 80$ & 0.0 & 1600 \\
\hline 9/ & 0.0 & 1610 \\
\hline $9 /$ & $\begin{array}{l}0.0 \\
0.0\end{array}$ & $\begin{array}{l}1720 \\
1820\end{array}$ \\
\hline $\begin{array}{l}9 / 1 / 80 \\
9 / 1 / 80\end{array}$ & $\begin{array}{l}0.0 \\
0.0\end{array}$ & $\begin{array}{l}1820 \\
{ }_{2000}\end{array}$ \\
\hline $\begin{array}{l}9 / 1 / 80 \\
9 / 170\end{array}$ & $\begin{array}{l}0.0 \\
0.0\end{array}$ & $\begin{array}{l}2000 \\
2040\end{array}$ \\
\hline & 0.0 & 2050 \\
\hline & 0.0 & 2140 \\
\hline & 0.0 & 2150 \\
\hline & 0.0 & 2230 \\
\hline & 0.0 & 2240 \\
\hline $\begin{array}{l}10 / 1 / 180 \\
10 / 1 / 80\end{array}$ & $\begin{array}{l}0.0 \\
0.0\end{array}$ & $\begin{array}{l}0020 \\
0030\end{array}$ \\
\hline $\begin{array}{l}10 / 1 / 70 \\
10 / 1 / 80\end{array}$ & $\begin{array}{l}0.0 \\
0.0\end{array}$ & $\begin{array}{l}\begin{array}{l}0030 \\
0330\end{array} \\
0.0\end{array}$ \\
\hline $\begin{array}{l}10 / 1 / 80 \\
10 / 70\end{array}$ & 0.0 & O6530 \\
\hline $10 / 1 /$ & 0.0 & 0700 \\
\hline & 0.0 & \\
\hline $10 / 1 / 80$ & 0.0 & 0740 \\
\hline $\begin{array}{l}10 / 1 / 80 \\
100\end{array}$ & 0.0 & 0930 \\
\hline $\begin{array}{l}10 / 1 / 80 \\
10 / 1 / 80\end{array}$ & $\begin{array}{l}0.0 \\
0.0\end{array}$ & 09940 \\
\hline $\begin{array}{l}10 / 1 / 80 \\
10 / 1 / 80\end{array}$ & $\begin{array}{l}0.0 \\
0.0\end{array}$ & $\begin{array}{l}0950 \\
1030\end{array}$ \\
\hline $\begin{array}{l}10 / 1 / 80 \\
1\end{array}$ & 0.0 & 1040 \\
\hline $10 / 1 /$ & 0.0 & 1310 \\
\hline $10 / 1 / 80$ & 0.0 & 1320 \\
\hline $\begin{array}{l}10 / 1 / 80 \\
10 / 1 / 80\end{array}$ & $\begin{array}{l}0.0 \\
0.0\end{array}$ & $\begin{array}{l}1620 \\
1920\end{array}$ \\
\hline & & \\
\hline
\end{tabular}

Table 1. (Continued).

\begin{tabular}{|c|c|c|c|}
\hline $\begin{array}{l}\text { Day/Month } \\
\text { Year }\end{array}$ & $\begin{array}{l}\text { Time } \\
\text { Zone }\end{array}$ & Time & $\begin{array}{l}\text { Latitude } \\
\text { (م) (min.) }\end{array}$ \\
\hline $10 / 1 / 80$ & 0.0 & 2220 & -5318.60 \\
\hline $11 / 1 / 80$ & 0.0 & $\begin{array}{l}0120 \\
0420\end{array}$ & $\begin{array}{r}-5313.73 \\
-53.88\end{array}$ \\
\hline $\begin{array}{l}1111 / 1 / 180 \\
11 / 1 / 80\end{array}$ & $\begin{array}{l}0.0 \\
0.0\end{array}$ & $\begin{array}{l}0420 \\
0720\end{array}$ & $\begin{array}{ll}-33 & 8.81 \\
-53 & 3.88\end{array}$ \\
\hline $11 / 1 / 80$ & 0.0 & 1020 & \\
\hline $\begin{array}{l}11 / 1 / 80 \\
11 / 80\end{array}$ & $\begin{array}{l}0.0 \\
0.0\end{array}$ & $\begin{array}{l}1320 \\
1620\end{array}$ & $\begin{array}{l}-5254.03 \\
-525491\end{array}$ \\
\hline $\begin{array}{l}11 / 1 / 180 \\
11 / 1 / 80\end{array}$ & $\begin{array}{l}0.0 \\
0.0\end{array}$ & $\begin{array}{l}1620 \\
1920\end{array}$ & $\begin{array}{l}-5249.10 \\
-52\end{array}$ \\
\hline $\begin{array}{l}11 / 1 / 180 \\
11 / 1 / 180\end{array}$ & $\begin{array}{l}0.0 \\
0.0\end{array}$ & $\begin{array}{l}1920 \\
2220\end{array}$ & $\begin{array}{l}-52 \\
-5239.26 \\
-52.26\end{array}$ \\
\hline $12 / 1 / 80$ & 0.0 & 0120 & $-52 \quad 34.33$ \\
\hline $12 / 1 / 80$ & 0.0 & 0420 & $\begin{array}{l}52 \\
-59.41\end{array}$ \\
\hline $12 / 1 / 80$ & 0.0 & 0500 & -5228.31 \\
\hline $12 / 1 / 80$ & 0.0 & 0510 & $\begin{array}{rl}-52 & 27.88 \\
& 07\end{array}$ \\
\hline $\begin{array}{l}12 / 1 / 80 \\
12 / 80\end{array}$ & 0.0 & $\begin{array}{l}0520 \\
05530\end{array}$ & $\begin{array}{l}-5226.05 \\
-52255\end{array}$ \\
\hline $\begin{array}{l}12 / 1 / 80 \\
12 / 180\end{array}$ & $\begin{array}{l}0.0 \\
0.0\end{array}$ & $\begin{array}{l}0530 \\
0550\end{array}$ & $\begin{array}{l}-52 \\
-525.21 \\
-52.24 .43\end{array}$ \\
\hline $\begin{array}{l}12 / 1 / 80 \\
12 / 1 / 80\end{array}$ & $\begin{array}{l}0.0 \\
0.0\end{array}$ & $\begin{array}{l}05550 \\
0850\end{array}$ & $\begin{array}{l}-5222.493 \\
-52.2602\end{array}$ \\
\hline $\begin{array}{l}12 / 7800 \\
12 / 1 / 80\end{array}$ & $\begin{array}{l}0.0 \\
0.0\end{array}$ & $\begin{array}{l}\text { i150 } \\
1150\end{array}$ & $\begin{array}{l}-5220.02 \\
-5228.02\end{array}$ \\
\hline $12 / 1 / 80$ & 0.0 & 1400 & $\begin{array}{l}-52 \\
-29.39\end{array}$ \\
\hline $12 / 1 / 80$ & 0.0 & 1410 & -5229.43 \\
\hline $12 / 1 / 80$ & 0.0 & 1710 & $\begin{array}{r}-5230.89 \\
-\end{array}$ \\
\hline $12 / 1 / 80$ & 0.0 & $\begin{aligned} 2010 \\
2310\end{aligned}$ & $\begin{array}{r}-5232.30 \\
-52.313\end{array}$ \\
\hline $\begin{array}{l}12 / 1 / 80 \\
13 / 1 / 80\end{array}$ & $\begin{array}{l}0.0 \\
0.0\end{array}$ & $\begin{array}{l}2310 \\
0020\end{array}$ & $\begin{array}{l}-52 \\
-5234.84 \\
-523436\end{array}$ \\
\hline $\begin{array}{l}13 / 1 / 1 / 80 \\
13 / 1 / 80\end{array}$ & $\begin{array}{l}0.0 \\
0.0\end{array}$ & $\begin{array}{l}0020 \\
0320\end{array}$ & $\begin{array}{l}-52 \\
-52223.36 \\
-52\end{array}$ \\
\hline $\begin{array}{l}13 / 7 / 780 \\
13 / 1 / 80\end{array}$ & $\begin{array}{l}0.0 \\
0.0\end{array}$ & $\begin{array}{l}0320 \\
0620\end{array}$ & $\begin{array}{l}-52 \\
-52\end{array} 21.54$ \\
\hline $13 / 1 / 80$ & 0.0 & 0750 & $\begin{array}{ll}-52 & 18.20\end{array}$ \\
\hline $13 / 1 / 80$ & 0.0 & 0850 & $-52 \quad 15.30$ \\
\hline $13 / 1 / 80$ & 0.0 & 0930 & -5213.24 \\
\hline $13 / 1 / 80$ & 0.0 & 1100 & $\begin{array}{rr}-52 & 9.62\end{array}$ \\
\hline $\begin{array}{l}13 / 1 / 80 \\
13 / / 880\end{array}$ & $\begin{array}{l}0.0 \\
0.0\end{array}$ & $\begin{array}{l}1220 \\
1520\end{array}$ & $\begin{array}{ll}-52 & 6.45 \\
-52 & 1.48\end{array}$ \\
\hline $\begin{array}{l}13 / 1 / 180 \\
13 / / 80\end{array}$ & $\begin{array}{l}0.0 \\
0.0\end{array}$ & $\begin{array}{l}1520 \\
1820\end{array}$ & $\begin{array}{ll}-52 & 1.68 \\
-51 & 56.96\end{array}$ \\
\hline $\begin{array}{l}13 / 1 / 180 \\
13 / 80\end{array}$ & 0.0 & $\begin{array}{l}1820 \\
2120\end{array}$ & $\begin{array}{l}-513.260 \\
-5152.24\end{array}$ \\
\hline $14 / 1 / 80$ & 0.0 & 0020 & $\begin{array}{lll}-51 & 47.51\end{array}$ \\
\hline $14 / 1 / 80$ & 0.0 & 0240 & -5143.84 \\
\hline $14 / 1 / 80$ & 0.0 & 0540 & -5139.89 \\
\hline $14 / 1 / 80$ & 0.0 & 00610 & $\begin{array}{l}-51 \\
-51 \\
-513.113\end{array}$ \\
\hline $\begin{array}{l}14 / 1 / 80 \\
14 / 1 / 80\end{array}$ & $\begin{array}{l}0.0 \\
0.0\end{array}$ & $\begin{array}{l}0720 \\
1020\end{array}$ & $\begin{array}{l}-5137.22 \\
-5132.81\end{array}$ \\
\hline $\begin{array}{l}14 / 1 / 80 \\
14 / 1 / 80\end{array}$ & $\begin{array}{l}0.0 \\
0.0\end{array}$ & $\begin{array}{l}1020 \\
1040\end{array}$ & $\begin{array}{l}-5132.81 \\
-5132.30\end{array}$ \\
\hline $\begin{array}{l}14 / 1 / 80 \\
14 / 1 / 80\end{array}$ & 0.0 & 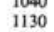 & $\begin{array}{ll}-51 \\
-51 & 30.76\end{array}$ \\
\hline $14 / 1 / 80$ & 0.0 & 1230 & -5129.06 \\
\hline $14 / 1 / 80$ & 0.0 & 1320 & $\begin{array}{ll}-51 & 27.92\end{array}$ \\
\hline $14 / 1 / 80$ & 0.0 & 1510 & $\begin{array}{l}-51 \quad 25.04 \\
\end{array}$ \\
\hline $14 / 1 / 80$ & 0.0 & 1550 & $\begin{aligned}-5123.93 \\
-51\end{aligned}$ \\
\hline $\begin{array}{l}14 / 1 / 80 \\
14 / 1 / 80\end{array}$ & $\begin{array}{l}0.0 \\
0.0\end{array}$ & $\begin{array}{l}1610 \\
1840\end{array}$ & $\begin{array}{l}-5123.77 \\
-5119.86\end{array}$ \\
\hline $\begin{array}{l}14 / 1 / 80 \\
14 / 1 / 80\end{array}$ & $\begin{array}{l}0.0 \\
0.0\end{array}$ & $\begin{array}{l}1840 \\
2010\end{array}$ & $\begin{array}{l}-5119.86 \\
-5118.20\end{array}$ \\
\hline $\begin{array}{l}14 / 1 / 80 \\
14 / 1 / 80\end{array}$ & $\begin{array}{l}0.0 \\
0.0\end{array}$ & $\begin{array}{l}2010 \\
2310\end{array}$ & $\begin{array}{rl}-51 & 18.20 \\
-51 & 13.37\end{array}$ \\
\hline $15 / 1 / 80$ & 0.0 & 0210 & $\begin{array}{l}-51.34 \\
\end{array}$ \\
\hline $15 / 1 / 80$ & 0.0 & 0450 & -514.18 \\
\hline $15 / 1 / 80$ & 0.0 & 0510 & $\begin{array}{ll}-51 & 3.97\end{array}$ \\
\hline $15 / 1 / 80$ & 0.0 & 0610 & $\begin{array}{ll}-51 & 3.52 \\
-51 & 3\end{array}$ \\
\hline $\begin{array}{l}15 / 1 / 80 \\
15 / 1 / 80\end{array}$ & $\begin{array}{l}0.0 \\
0.0\end{array}$ & $\begin{array}{l}0630 \\
0640\end{array}$ & $\begin{array}{ll}-51 & 3.50 \\
-51 & 3.50\end{array}$ \\
\hline $\begin{array}{l}151 / 1 / 180 \\
15 / 1 / 80\end{array}$ & $\begin{array}{l}0.0 \\
0.0\end{array}$ & 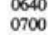 & $\begin{array}{ll}-51 & 3.30 \\
-51 & 3.50\end{array}$ \\
\hline $15 / 1 / 80$ & 0.0 & 0710 & $\begin{array}{ll}-51 & 3.55\end{array}$ \\
\hline $15 / 1 / 80$ & 0.0 & 0720 & $\begin{array}{lll}-51 & 3.67\end{array}$ \\
\hline $15 / 1 / 80$ & 0.0 & 0730 & $\begin{array}{r}-51 \\
-51.95\end{array}$ \\
\hline $15 / 1 / 80$ & 0.0 & 0820 & $\begin{array}{r}-50 \\
59.24\end{array}$ \\
\hline $\begin{array}{l}15 / 1 / 80 \\
15 / 1 / 80\end{array}$ & $\begin{array}{l}0.0 \\
0.0\end{array}$ & $\begin{array}{l}0840 \\
0910 \\
0910\end{array}$ & $\begin{array}{ll}-5057,47 \\
-51 & 0,20\end{array}$ \\
\hline $\begin{array}{l}15 / 1 / 80 \\
\end{array}$ & 0.0 & 0920 & $\begin{array}{ll}-51 & 0.30\end{array}$ \\
\hline $21 / 1 / 80$ & 0.0 & 0845 & - 5059.93 \\
\hline $21 / 1 / 80$ & 0.0 & 1145 & - 5050.99 \\
\hline $\begin{array}{l}21 / 1 / 80 \\
21 / 1 / 80\end{array}$ & $\begin{array}{l}0.0 \\
0.0\end{array}$ & $\begin{array}{l}1445 \\
1745\end{array}$ & $\begin{array}{l}-5042.44 \\
-5033,04\end{array}$ \\
\hline $21 / 1 / 80$ & $\begin{array}{l}0.0 \\
0.0\end{array}$ & 2045 & $\begin{array}{r}-50 \\
-5026.29\end{array}$ \\
\hline $21 / 1$ & 0.0 & 2305 & -5020.31 \\
\hline & 0.0 & 0135 & -5015.05 \\
\hline $22 / 1 / 80$ & 0.0 & 0435 & $-50 \quad 11.60$ \\
\hline & 0.0 & & $\begin{array}{rl}-50 & 11.06 \\
-50 & 10.70\end{array}$ \\
\hline & $\begin{array}{l}0.0 \\
0.0\end{array}$ & $\begin{array}{l}0505 \\
0.525\end{array}$ & $z$ \\
\hline 22/11 & 0.0 & 0535 & $\begin{array}{l}-50 \quad 9.63 \\
\end{array}$ \\
\hline $22 / 1 / 80$ & 0.0 & 0615 & $\begin{array}{ll}-50 & 8.54\end{array}$ \\
\hline & 0.0 & 0915 & $\begin{array}{lll}-50 & 0.75\end{array}$ \\
\hline $22 / 11$ & 0.0 & 0935 & $\begin{array}{r}-4959.93 \\
-\end{array}$ \\
\hline & 0.0 & 1015 & $\begin{array}{r}-4958.61 \\
-4988\end{array}$ \\
\hline $\begin{array}{l}2221 / 1 \\
22 / 1 /\end{array}$ & $\begin{array}{l}0.0 \\
0.0\end{array}$ & $\begin{array}{l}1255 \\
1255\end{array}$ & $\begin{array}{l}-49 \\
-4958.17\end{array}$ \\
\hline & 0.0 & 1305 & - \\
\hline $22 / 1 /$ & 0.0 & 1325 & -4953.73 \\
\hline & 0.0 & 1335 & -4953 \\
\hline $22 / 1 /$ & 0.0 & 1405 & -4952.20 \\
\hline $22 / 1 / 8$ & 0.0 & $\begin{array}{l}1415 \\
1350\end{array}$ & -4952.20 \\
\hline $27 / 1 / 1$ & $\begin{array}{l}0.0 \\
0.0\end{array}$ & $\begin{array}{l}1350 \\
1640\end{array}$ & $\begin{array}{l}-4952.11 \\
-4949.18\end{array}$ \\
\hline & & 165 & -4948.90 \\
\hline & & & -4948 \\
\hline & & & -4944 \\
\hline & 0.0 & 211 & $\begin{array}{r}-494.02 \\
4.02\end{array}$ \\
\hline & 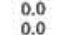 & $\begin{array}{l}2150 \\
2330 \\
2330\end{array}$ & $\begin{array}{l}-4944 \\
-4945\end{array}$ \\
\hline & & $\begin{array}{l}2330 \\
0000\end{array}$ & $\begin{array}{l}-494 \\
-494\end{array}$ \\
\hline & & $\infty$ & $\begin{array}{l}-4945 \\
-4946\end{array}$ \\
\hline & & & \\
\hline & 0 & & \\
\hline & & & -492 \\
\hline & 0.0 & 0310 & -4934.30 \\
\hline & 0.0 & & -1 \\
\hline & 0.0 & 0620 & -4920.60 \\
\hline & 0.0 & $\begin{array}{l}0630 \\
0600\end{array}$ & -4920.07 \\
\hline $\begin{array}{l}28 / 1 \\
28 / 1\end{array}$ & $\begin{array}{l}0.0 \\
0.0\end{array}$ & $\begin{array}{l}0700 \\
0710\end{array}$ & $\begin{array}{l}-4919.14 \\
-4918.76\end{array}$ \\
\hline $28 / 1 /$ & 0.0 & 0720 & -4918.31 \\
\hline & 0.0 & 0820 & -4912.90 \\
\hline $1 / 180$ & 0.0 & 0910 & -498.24 \\
\hline
\end{tabular}


Table 1. (Continued).

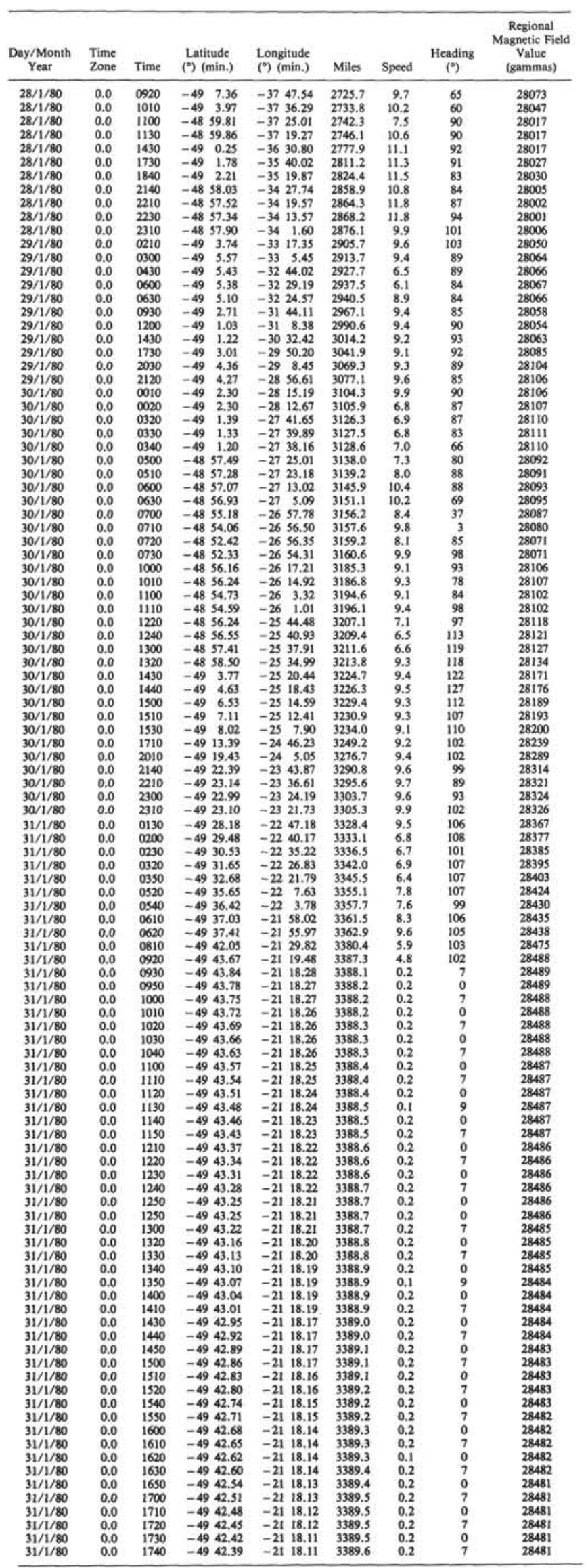

Table 1. (Continued).

\begin{tabular}{|c|c|c|c|c|c|c|c|c|}
\hline $\begin{array}{c}\text { Day/Month } \\
\text { Year } \\
\end{array}$ & $\begin{array}{l}\text { Time } \\
\text { Zone }\end{array}$ & Time & $\begin{array}{l}\text { Latitude } \\
\left({ }^{\circ} \text { (min.) }\right.\end{array}$ & $\begin{array}{l}\text { Longitude } \\
\left({ }^{\circ} \text { (min.) }\right.\end{array}$ & Miles & Speed & $\begin{array}{c}\text { Heading } \\
\left({ }^{\circ}\right)\end{array}$ & $\begin{array}{c}\text { Regional } \\
\text { Magnetic Field } \\
\text { Value } \\
\text { (gammas) }\end{array}$ \\
\hline $31 / 1 / 80$ & 0.0 & $\begin{array}{l}1800 \\
1810\end{array}$ & -4942.33 & $\begin{array}{rl}21 & 18.10\end{array}$ & 3389.6 & 0.2 & 0 & 28480 \\
\hline $\begin{array}{l}31 / 1 / 180 \\
31 / 1 / 80\end{array}$ & $\begin{array}{l}0.0 \\
0.0\end{array}$ & $\begin{array}{l}1810 \\
1820\end{array}$ & $\begin{array}{l}-49422.30 \\
-4942.27\end{array}$ & $\begin{array}{lll}-21 & 18.10 \\
-2 & 18.10\end{array}$ & $\begin{array}{l}3389.7 \\
33989\end{array}$ & 0.2 & $?$ & $\begin{array}{r}28480 \\
-2408\end{array}$ \\
\hline $31 / 1 / 80$ & 0.0 & $\begin{array}{l}1820 \\
1830\end{array}$ & $\begin{array}{l}-49422.27 \\
-4942.24\end{array}$ & $\begin{array}{l}-211 \\
-21 \\
-218.10\end{array}$ & $\begin{array}{l}338989.7 \\
3389.7\end{array}$ & $\begin{array}{l}0.2 \\
0.1\end{array}$ & $\stackrel{0}{9}$ & $\begin{array}{l}{ }_{28480} 28480 \\
280\end{array}$ \\
\hline $31 / 1 / 80$ & 0.0 & 1840 & -4942.22 & $\begin{array}{rl}-21 & 18.09\end{array}$ & 3389.7 & 0.2 & 0 & 28479 \\
\hline $\begin{array}{l}31 / 1 / 180 \\
31 / 1 / 80\end{array}$ & $\begin{array}{l}0.0 \\
0.0\end{array}$ & $\begin{array}{l}1850 \\
1900 \\
190\end{array}$ & $\begin{array}{l}-4942.19 \\
-4942.13\end{array}$ & $\begin{array}{lll}-21 & 18.09 \\
-2 & 18.08\end{array}$ & $\begin{array}{l}3389.8 \\
33898\end{array}$ & 0.2 & 7 & $\begin{aligned} 28479 \\
28707\end{aligned}$ \\
\hline $\begin{array}{l}31 / 1 / 180 \\
31 / 1 / 80\end{array}$ & $\begin{array}{l}0.0 \\
0.0\end{array}$ & $\begin{array}{l}1910 \\
1920\end{array}$ & $\begin{array}{l}-4442.13 \\
-4942.10\end{array}$ & $\begin{array}{l}-2118.08 \\
-2118.08\end{array}$ & $\begin{array}{l}3389.8 \\
3398.9\end{array}$ & $\begin{array}{l}0.2 \\
0.2\end{array}$ & $\begin{array}{l}0 \\
7\end{array}$ & $\begin{array}{l}28479 \\
2849 \\
2879\end{array}$ \\
\hline $31 / 1 / 80$ & 0.0 & 1930 & -4942.07 & $\begin{array}{l}-21 \\
-218.07\end{array}$ & $\begin{array}{l}33389.9 \\
3389\end{array}$ & $\begin{array}{l}0.2 \\
0.2\end{array}$ & ${ }_{0}^{7}$ & $\begin{array}{l}284479 \\
28479\end{array}$ \\
\hline & 0.0 & 1940 & -4942.04 & $\begin{array}{lll}-21 & 18.07\end{array}$ & 3389.9 & 0.2 & 7 & $\begin{array}{l}284798 \\
2847\end{array}$ \\
\hline $\begin{array}{l}\begin{array}{l}31 / 1 / 1 / 180 \\
31 / 1 / 80\end{array} \\
3\end{array}$ & 0.0 & 1950 & -4942.01 & & 3390.0 & 0.2 & 0 & $\begin{array}{l}28478 \\
28478\end{array}$ \\
\hline $\begin{array}{l}31 / 1 / 780 \\
31 / 1 / 80\end{array}$ & $\begin{array}{l}0.0 \\
0.0\end{array}$ & ${ }_{2020}^{2000}$ & $\begin{array}{l}-4941.98 \\
-49.92\end{array}$ & $\begin{array}{rl}-21 & 18.07\end{array}$ & 3390.0 & 0.2 & 7 & 28478 \\
\hline $31 / 1 / 80$ & $\begin{array}{l}0.0 \\
0.0\end{array}$ & 2030 & $\begin{array}{l}-4941.92 \\
-4941.89\end{array}$ & $\begin{array}{l}-2118.05 \\
-2118.05\end{array}$ & $\begin{array}{l}3390.0 \\
33000\end{array}$ & 0.2 & $\stackrel{0}{7}$ & 28478 \\
\hline $31 / 1 / 80$ & 0.0 & 2040 & -4941.86 & -2118.05 & $\begin{array}{l}33990.1 \\
3390.1\end{array}$ & $\begin{array}{l}0.2 \\
0.2\end{array}$ & $?$ & $\begin{aligned} 28478 \\
28477\end{aligned}$ \\
\hline $31 / 1 / 80$ & 0.0 & 2050 & -4941.83 & -2118.05 & 3390.1 & 0.2 & $\begin{array}{l}0 \\
7\end{array}$ & $\begin{array}{l}\begin{array}{l}28477 \\
28477\end{array} \\
2\end{array}$ \\
\hline $31 / 1 / 80$ & 0.0 & 2100 & -4941.80 & $-21 \quad 18.04$ & 3390.2 & 0.1 & ${ }_{0}^{7}$ & $\begin{array}{l}28477 \\
28477\end{array}$ \\
\hline $31 / 1 / 80$ & 0.0 & 2110 & -4941.77 & $-21 \quad 18.04$ & 3390.2 & & 7 & 28477 \\
\hline & 0.0 & $\begin{array}{l}2130 \\
2130\end{array}$ & -4941.71 & & 3390.3 & 0.2 & 0 & 28477 \\
\hline $\begin{array}{l}31 / 1 / 180 \\
31 / 1 / 80\end{array}$ & $\begin{array}{l}0.0 \\
0.0\end{array}$ & $\begin{array}{l}2140 \\
21100\end{array}$ & -4941.68 & $\begin{array}{l}-21 \\
-218.03\end{array}$ & $\begin{array}{l}3390.3 \\
3300.3\end{array}$ & 0.2 & 7 & 28476 \\
\hline $31 / 1 / 80$ & 0.0 & $\begin{array}{l}2150 \\
2200 \\
200\end{array}$ & $\begin{array}{l}-4941.65 \\
-4941.62\end{array}$ & $\begin{array}{l}-2118.02 \\
-21 \quad 18.02\end{array}$ & 3390.3 & 0.2 & 0 & $\begin{array}{r}28476 \\
20176\end{array}$ \\
\hline $31 / 1 / 80$ & 0.0 & 2210 & $\begin{array}{l}-4941.59 \\
\end{array}$ & $\begin{array}{l}-211 \\
-21 \\
-18.02\end{array}$ & $\begin{array}{l}3399.3 \\
3390.4\end{array}$ & $\begin{array}{l}0.2 \\
0.2\end{array}$ & $?$ & $\begin{array}{l}28476 \\
28476\end{array}$ \\
\hline $31 / 1 / 80$ & 0.0 & 2220 & -4941.56 & -2118.02 & $\begin{array}{l}33390.4 \\
3390.4\end{array}$ & $\begin{array}{l}0.2 \\
0.2\end{array}$ & $?$ & $\begin{array}{l}28476 \\
28476\end{array}$ \\
\hline $31 / 1 / 80$ & 0.0 & 2240 & -4941.50 & $\begin{array}{lll}-21 & 18.01\end{array}$ & 3390.5 & 0.2 & $\begin{array}{l}7 \\
0\end{array}$ & $\begin{array}{l}284476 \\
2845\end{array}$ \\
\hline $31 / 1 / 80$ & 0.0 & 2250 & -4941.47 & -2118.01 & 3390.5 & & 7 & 28475 \\
\hline $31 / 1 / 80$ & 0.0 & 2300 & -4941.44 & -2118.00 & & 0.2 & 0 & 28475 \\
\hline $\begin{array}{l}31 / 1 / 80 \\
31 / 180\end{array}$ & 0.0 & $\begin{array}{l}2310 \\
2320\end{array}$ & -4941.41 & $\begin{array}{l}-2118.00 \\
\end{array}$ & 3390.6 & 0.2 & 7 & 28475 \\
\hline $\begin{array}{l}\begin{array}{l}31 / 1 / 1 / 180 \\
31 / 1 / 80\end{array} \\
3\end{array}$ & $\begin{array}{l}0.0 \\
0.0\end{array}$ & $\begin{array}{l}22320 \\
2330\end{array}$ & $\begin{array}{l}-49441.38 \\
-4941.36\end{array}$ & $\begin{array}{lll}-21 & 17.99 \\
-21 & 17.99\end{array}$ & 3390.6 & 0.1 & $\stackrel{0}{7}$ & $\begin{array}{r}28475 \\
20474\end{array}$ \\
\hline $\begin{array}{l}31 / 1 / 1 / 80 \\
31 / 10\end{array}$ & 0.0 & 2350 & $\begin{array}{l}-4941.30 \\
\end{array}$ & $\begin{array}{lll}-21 & 17.99 \\
-21 & 17.98\end{array}$ & $\begin{array}{l}3399.6 \\
3390.7\end{array}$ & $\begin{array}{l}0.2 \\
0.2\end{array}$ & $?$ & $\begin{aligned} 28474 \\
28474\end{aligned}$ \\
\hline $\begin{array}{r}1 / 2 / 80 \\
1 / 20\end{array}$ & 0.0 & 0000 & -4941.27 & $-21 \quad 17.98$ & 3390.7 & 0.2 & 7 & $\begin{array}{l}28474 \\
28474\end{array}$ \\
\hline $1 / 2 / 80$ & 0.0 & 0010 & -4941.24 & $\begin{array}{lll}-21 & 17.98\end{array}$ & 3390.7 & 0.2 & 0 & $\begin{array}{l}{ }_{28474}^{2847} \\
284\end{array}$ \\
\hline $1 / 2 / 80$ & 0.0 & 0020 & -4941.21 & -2117.98 & & & 7 & 28474 \\
\hline & 0.0 & & -4941.18 & $\begin{array}{lll}-21 & 17.97\end{array}$ & 3390.8 & 0.2 & 0 & 28473 \\
\hline $1 / 2 / 80$ & 0.0 & 0040 & -4941.15 & $\begin{array}{lll}-21 & 17.97\end{array}$ & 3390.8 & 0.2 & 7 & 28473 \\
\hline $1 / 2 / 80$ & 0.0 & 0100 & -4941.09 & $\begin{array}{l}-211 \\
17.96\end{array}$ & $\begin{array}{l}3390.9 \\
37009\end{array}$ & 0.2 & 0 & 28473 \\
\hline $\begin{array}{l}1 / 2 / 80 \\
1 / 2 / 80\end{array}$ & $\begin{array}{l}0.0 \\
0.0\end{array}$ & $\begin{array}{l}0110 \\
0120\end{array}$ & $\begin{array}{l}-4941.06 \\
-4941.03\end{array}$ & $\begin{array}{ll}-21 & 17.96 \\
-21 & 17.95\end{array}$ & $\begin{array}{l}3390.9 \\
3390.9\end{array}$ & $\begin{array}{l}0.2 \\
0.2\end{array}$ & $?$ & $\begin{array}{l}28473 \\
28473\end{array}$ \\
\hline $\begin{array}{l}1 / 2 / 2 / 80 \\
11 / 80\end{array}$ & $\begin{array}{l}0.0 \\
0.0\end{array}$ & $\begin{array}{l}0120 \\
0130\end{array}$ & $\begin{array}{l}-49441.03 \\
-4941.00\end{array}$ & $\begin{array}{ll}-21 & 17.95 \\
-21 & 17.95\end{array}$ & $\begin{array}{l}3390.9 \\
3391.0\end{array}$ & $\begin{array}{l}0.2 \\
0.2\end{array}$ & $\begin{array}{l}0 \\
7\end{array}$ & $\begin{array}{l}{ }_{28473}^{28472} \\
2842\end{array}$ \\
\hline $1 / 2 / 80$ & 0.0 & 0140 & -4940.97 & -2117.95 & 3391.0 & & ${ }_{0}^{7}$ & $\begin{array}{l}284472 \\
28472\end{array}$ \\
\hline $1 / 2 / 80$ & 0.0 & 0150 & -4940.94 & -2117.95 & 3391.0 & 0.2 & 7 & 28472 \\
\hline $1 / 2 / 80$ & 0.0 & 0210 & -4940.88 & $-21 \quad 17.93$ & 3391.1 & 0.2 & 0 & 28472 \\
\hline $1 / 2 / 80$ & 0.0 & 0220 & -4940.85 & -2117.93 & 3391.1 & 0.2 & 7 & 28472 \\
\hline $\begin{array}{l}1 / 2 / 80 \\
1 / 2 / 80\end{array}$ & $\begin{array}{l}0.0 \\
0.0\end{array}$ & 0230 & -4940.82 & $\begin{array}{rl}-21 & 17.93 \\
\end{array}$ & 3391.1 & 0.2 & 0 & 28471 \\
\hline $\begin{array}{l}\begin{array}{l}1 / 2 / 80 \\
1 / 2 / 80\end{array}\end{array}$ & $\begin{array}{l}0.0 \\
0.0\end{array}$ & $\begin{array}{l}2240 \\
0250\end{array}$ & $\begin{array}{r}-4940.79 \\
-4940.76\end{array}$ & $\begin{array}{l}-21 \\
-21 \\
-117.93\end{array}$ & $\begin{array}{l}3399.2 \\
3391.2\end{array}$ & $\begin{array}{l}0.2 \\
0.2\end{array}$ & $?$ & $\begin{array}{l}28471 \\
28471\end{array}$ \\
\hline $1 / 2 / 80$ & 0.0 & 0300 & $\begin{array}{l}-4940.73 \\
\end{array}$ & $\begin{array}{l}-21 \\
-21 \\
-17.92 \\
\end{array}$ & 3391.2 & $\begin{array}{l}0.2 \\
0.2\end{array}$ & ${ }_{7}^{0}$ & $\begin{array}{l}284711 \\
28471\end{array}$ \\
\hline $\begin{array}{l}1 / 2 / 80 \\
1 / 2 / 80\end{array}$ & $\begin{array}{l}0.0 \\
0.0\end{array}$ & $\begin{array}{l}0320 \\
0330\end{array}$ & -4940.67 & $\begin{array}{l}-21 \\
-217.91\end{array}$ & & 0.2 & 0 & $\begin{array}{l}28470 \\
28470\end{array}$ \\
\hline $\begin{array}{l}1 / 2 / 80 \\
1 / 2 / 80\end{array}$ & $\begin{array}{l}0.0 \\
0.0\end{array}$ & $\begin{array}{l}03330 \\
0340\end{array}$ & $\begin{array}{l}-4994.64 \\
-49 \\
-40.61\end{array}$ & $\begin{array}{l}-21 \\
-21 \\
-117.91 \\
\end{array}$ & $\begin{array}{l}3399.3 \\
3391.4\end{array}$ & $\begin{array}{l}0.2 \\
0.2\end{array}$ & $?$ & $\begin{array}{l}{ }_{28470}^{28470} \\
287\end{array}$ \\
\hline $1 / 2 / 80$ & 0.0 & 0350 & -4940.58 & $\begin{array}{l}-21 \\
-21 \\
17.90\end{array}$ & 3391.4 & 0.2 & $\begin{array}{l}0 \\
7\end{array}$ & $\begin{array}{l}28470 \\
28470\end{array}$ \\
\hline $\begin{array}{l}1 / 2 / 280 \\
1 / 2 / 80\end{array}$ & $\begin{array}{l}0.0 \\
0.0\end{array}$ & $\begin{array}{l}0440 \\
0.10\end{array}$ & $\begin{array}{l}-4940.55 \\
-4940.52\end{array}$ & $\begin{array}{l}-21 \\
-21 \\
-217.90\end{array}$ & $\begin{array}{l}3391.4 \\
3390.4\end{array}$ & 0.2 & 8 & 28470 \\
\hline $\begin{array}{l}1 / 2 / 80 \\
1 / 20\end{array}$ & 0.0 & $\begin{array}{l}0.0410 \\
0430\end{array}$ & $\begin{array}{l}-49404.32 \\
-4940.47\end{array}$ & 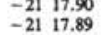 & $\begin{array}{l}3391.4 \\
3391.5\end{array}$ & $\begin{array}{l}0.2 \\
0.2\end{array}$ & ${ }_{0}^{8}$ & $\begin{array}{l}28470 \\
28469\end{array}$ \\
\hline $1 / 2 / 80$ & 0.0 & 0440 & -4940.44 & -21177.89 & 3391.5 & 0.2 & $\stackrel{0}{7}$ & $\begin{array}{l}284699 \\
28469\end{array}$ \\
\hline $\begin{array}{l}1 / 2 / 80 \\
1 / 2880\end{array}$ & $\begin{array}{l}0.0 \\
0.0\end{array}$ & $\begin{array}{l}0450 \\
0.500\end{array}$ & $\begin{array}{l}-4940.414 \\
-4940.38\end{array}$ & $\begin{array}{ll}-21 & 17.88 \\
-21 & 17.88\end{array}$ & $\begin{array}{l}3391.6 \\
3391.6\end{array}$ & 0.2 & 0 & 28469 \\
\hline $\begin{array}{l}1 / 2 / 80 \\
1 / 20\end{array}$ & 0.0 & 0510 & $\begin{array}{r}-49 \\
-40.38\end{array}$ & $\begin{array}{lll}-21 & 17.88 \\
-21 & 17.87\end{array}$ & $\begin{array}{l}3399.6 \\
3391.6\end{array}$ & $\begin{array}{l}0.2 \\
0.2\end{array}$ & $\begin{array}{l}7 \\
0\end{array}$ & $\begin{array}{l}28469 \\
28469\end{array}$ \\
\hline $1 / 2 / 80$ & 0.0 & 0520 & -4940.32 & $\begin{array}{lll}-21 & 17.87\end{array}$ & 3391.7 & 0.2 & $\begin{array}{l}0 \\
7\end{array}$ & $\begin{array}{l}28469 \\
28468\end{array}$ \\
\hline $\begin{array}{l}1 / 2 / 280 \\
1 / 2 / 80\end{array}$ & $\begin{array}{l}0.0 \\
0.0\end{array}$ & $\begin{array}{l}0540 \\
0.550\end{array}$ & $\begin{array}{l}-4940.26 \\
\end{array}$ & $\begin{array}{ll}-21 & 17.86 \\
-217\end{array}$ & 3391.7 & 0.2 & 0 & $\begin{array}{l}28468 \\
2848\end{array}$ \\
\hline $1 / 2 / 80$ & $\begin{array}{l}0.0 \\
0.0\end{array}$ & $\begin{array}{l}0550 \\
0600\end{array}$ & $\begin{array}{l}-4940.23 \\
-4940.20\end{array}$ & $\begin{array}{ll}-21 & 17.86 \\
-21 & 17.86\end{array}$ & $\begin{array}{l}3391.7 \\
3391.8\end{array}$ & $\begin{array}{l}0.2 \\
0.2\end{array}$ & $?$ & $\begin{array}{l}{ }_{28468}^{28468} \\
2848\end{array}$ \\
\hline $1 / 2 / 80$ & 0.0 & 0610 & $\begin{array}{r}-49 \\
40.17\end{array}$ & $\begin{array}{l}-2117.86 \\
\end{array}$ & $\begin{array}{l}3391.8 \\
3391.8\end{array}$ & 0.2 & $?$ & $\begin{array}{l}28486 \\
28468\end{array}$ \\
\hline $\begin{array}{l}1 / 2 / 280 \\
1 / 2 / 80\end{array}$ & 0.0 & $\begin{array}{l}0620 \\
0630\end{array}$ & -4940.14 & $\begin{array}{l}-21 \\
-2117.85\end{array}$ & 3391.8 & 0.2 & 0 & $\begin{array}{l}28467 \\
28467\end{array}$ \\
\hline $\begin{array}{l}1 / 2 / 80 \\
1 / 2 / 80\end{array}$ & $\begin{array}{l}0.0 \\
0.0\end{array}$ & $\begin{array}{l}\begin{array}{l}0630 \\
0650\end{array} \\
0.00\end{array}$ & $\begin{array}{l}-4940.111 \\
-490.06\end{array}$ & $\begin{array}{l}-21 \\
-21 \\
-217.88 \\
\end{array}$ & $\begin{array}{l}3391.9 \\
3391.9\end{array}$ & $\begin{array}{l}0.2 \\
0.2\end{array}$ & 8 & $\begin{array}{l}28467 \\
28467\end{array}$ \\
\hline $1 / 2 / 80$ & 0.0 & 0700 & -4940.03 & 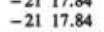 & $\begin{array}{l}3392.0 \\
339 .\end{array}$ & $\begin{array}{l}0.2 \\
0.2\end{array}$ & $\frac{0}{7}$ & $\begin{array}{l}28467 \\
28467\end{array}$ \\
\hline $\begin{array}{l}1 / 2 / 280 \\
1 / 2 / 80\end{array}$ & 0.0 & $\begin{array}{l}0710 \\
0720\end{array}$ & $\begin{array}{r}-49 \\
-40.00\end{array}$ & $\begin{array}{l}-2117.83 \\
\end{array}$ & 3392.0 & 0.2 & 0 & 28466 \\
\hline $\begin{array}{l}1 / 2 / 280 \\
1 / 2 / 80\end{array}$ & $\begin{array}{l}0.0 \\
0.0\end{array}$ & $\begin{array}{l}0720 \\
0730\end{array}$ & $\begin{array}{r}-4939.97 \\
-4439994\end{array}$ & $\begin{array}{l}-21 \\
-21 \\
-2117.83\end{array}$ & $\begin{array}{l}3392.0 \\
33920\end{array}$ & & 7 & $\begin{array}{l}28466 \\
28466\end{array}$ \\
\hline $1 / 2 / 80$ & 0.0 & $\begin{array}{l}0730 \\
0740\end{array}$ & $\begin{array}{r}-49 \\
-49.94 \\
-4939\end{array}$ & $\begin{array}{ll}-21 & 17.83 \\
-21 & 17.83\end{array}$ & $\begin{array}{l}3392.0 \\
3392.1\end{array}$ & $\begin{array}{l}0.2 \\
0.2\end{array}$ & $\stackrel{0}{7}$ & $\begin{array}{l}{ }_{284666}^{2846} \\
2846\end{array}$ \\
\hline & 0.0 & 0800 & -4939.85 & $\begin{array}{lll}-21 & 17.83\end{array}$ & 3392.1 & 0.2 & 0 & 28466 \\
\hline & & 0810 & -4939.82 & -2117.81 & 3392.2 & 0.2 & 7 & 28465 \\
\hline $1 / 2 /$ & 0.0 & 0820 & $\begin{array}{r}-4939.79 \\
\end{array}$ & -2117.81 & $\begin{array}{l}3392.2 \\
{ }_{37302}\end{array}$ & 0.2 & 0 & 28465 \\
\hline $\begin{array}{l}1 / 2 / 280 \\
1 / 2 / 80\end{array}$ & $\begin{array}{l}0.0 \\
0.0\end{array}$ & $\begin{array}{l}0830 \\
0840\end{array}$ & $\begin{array}{r}-4939.76 \\
-4937\end{array}$ & $\begin{array}{ll}-21 & 17.81\end{array}$ & & 0.2 & 0 & $\begin{array}{l}{ }_{284655}^{28465} \\
{ }_{2}\end{array}$ \\
\hline $1 / 2 / 80$ & 0.0 & 085 & -4939.70 & $\begin{array}{lll}-21 & 17.80\end{array}$ & 3392.3 & 0.1 & 9 & 28465 \\
\hline $1 / 2 / 80$ & 0.0 & 090 & -4939.67 & -2117.80 & & 7.3 & 301 & 28465 \\
\hline $1 / 2 / 80$ & 0.0 & & -493 & -21 & & 9. & & \\
\hline & $\begin{array}{l}0.0 \\
0.0\end{array}$ & 10 & & -21 & & 9.4 & & \\
\hline & $\begin{array}{l}0.0 \\
0.0\end{array}$ & $\begin{array}{l}1030 \\
1040\end{array}$ & $\begin{array}{l}-49 \\
-4933.96 \\
-432\end{array}$ & $\begin{array}{l}-2134.94 \\
-2137.17\end{array}$ & $\begin{array}{l}3405.0 \\
3406.6\end{array}$ & $\begin{array}{l}9.6 \\
9.7\end{array}$ & 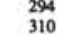 & $\begin{array}{l}28443 \\
28418\end{array}$ \\
\hline & 0.0 & 11 & -492 & -2144.72 & & 7.2 & & 28391 \\
\hline & $\begin{array}{l}0.0 \\
0.0\end{array}$ & ${ }_{13}^{11}$ & & $\begin{array}{l}45.88 \\
58.44\end{array}$ & & 6.4 & $\begin{array}{l}308 \\
306\end{array}$ & \\
\hline $\begin{array}{l}1 / 27 \\
1 / 2\end{array}$ & $\begin{array}{l}0.0 \\
0.0\end{array}$ & $\begin{array}{l}1300 \\
1350\end{array}$ & $\begin{array}{l}-4921.71 \\
-4918.39\end{array}$ & $\begin{array}{ll}-21 & 57.43 \\
-22 & 4.39\end{array}$ & $\begin{array}{l}3423.9 \\
3429.5\end{array}$ & $\begin{array}{l}6.8 \\
6.6\end{array}$ & $\begin{array}{l}306 \\
299 \\
299\end{array}$ & $\begin{array}{l}283346 \\
28324\end{array}$ \\
\hline & 0.0 & 1410 & -491 & & & 4.5 & & \\
\hline $\begin{array}{l}1 / 2 / 280 \\
1 / 2 / 80\end{array}$ & $\begin{array}{l}0.0 \\
0.0\end{array}$ & $\begin{array}{l}1430 \\
1600\end{array}$ & -4 & $\begin{array}{ll}-22 & 9.35 \\
-22 & 22.61\end{array}$ & $\begin{array}{l}3433.3 \\
3434.3\end{array}$ & 6.7 & $\begin{array}{l}300 \\
303 \\
3_{03}\end{array}$ & $\begin{array}{l}{ }_{28312}^{28327} \\
28278\end{array}$ \\
\hline $\begin{array}{l}1 / 2 / 280 \\
1 / 2 / 80\end{array}$ & $\begin{array}{l}0.0 \\
0.0\end{array}$ & $\begin{array}{l}1000 \\
1640\end{array}$ & $\begin{array}{l}-49111.53 \\
-49\end{array}$ & $\begin{array}{l}-22222.61 \\
-22 \\
-28.74\end{array}$ & $\begin{array}{l}3443.3 \\
3448.1\end{array}$ & 7.2 & $\begin{array}{l}\begin{array}{l}303 \\
314\end{array} \\
31\end{array}$ & $\begin{array}{l}282287 \\
28261\end{array}$ \\
\hline & 0.0 & 16 & -49 & -223 & 3449.3 & 8.9 & 320 & \\
\hline $1 / 2$ & $\begin{array}{l}0.0 \\
0.0\end{array}$ & $\begin{array}{l}1950 \\
2000\end{array}$ & $\begin{array}{l}-4847.45 \\
\end{array}$ & $\begin{array}{l}-2255.82 \\
\end{array}$ & $\begin{array}{l}3475.9 \\
342.9\end{array}$ & 9.1 & 314 & $\begin{array}{l}28128 \\
28099\end{array}$ \\
\hline & $\begin{array}{l}.0 .0 \\
0.0\end{array}$ & $\begin{array}{l}2040 \\
2110\end{array}$ & $\begin{array}{l}-48482.12 \\
-48 \\
-49.04\end{array}$ & $\begin{array}{ll}-23 & 4.04 \\
-23 & 9.89\end{array}$ & 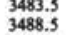 & $\begin{array}{l}9.9 \\
9.8\end{array}$ & 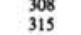 & $\begin{array}{l}289095 \\
28076\end{array}$ \\
\hline & & & & & & & & \\
\hline & & & & -23 & & & & \\
\hline & & & -48 & -23 & & & & 27905 \\
\hline & & & & & & & & $\begin{array}{l}27882 \\
27847\end{array}$ \\
\hline & $\begin{array}{l}0.0 \\
0.0\end{array}$ & & $\begin{array}{l}-48 \\
-47,5\end{array}$ & & & 6 & $\begin{array}{l}3100 \\
315\end{array}$ & \\
\hline & 0.0 & 045 & -475 & -242 & & 6. & 321 & 27803 \\
\hline & 0.0 & & & & & & 29 & \\
\hline & 0.0 & 080 & & & 3572.0 & 6.5 & 327 & $\begin{array}{l}27710 \\
27690\end{array}$ \\
\hline & $\begin{array}{l}0.0 \\
0.0\end{array}$ & $\begin{array}{l}084 \\
085\end{array}$ & $\begin{array}{l}-47734.87 \\
-47 \\
-44.11\end{array}$ & $\begin{array}{l}-2438.38 \\
-2439.04\end{array}$ & 77.2 & $\begin{array}{l}5.1 \\
0.7\end{array}$ & $\begin{array}{l}\begin{array}{l}238 \\
131\end{array}\end{array}$ & $\begin{array}{l}276699 \\
27685\end{array}$ \\
\hline & 0.0 & 09 & -473 & & & 0.0 & 17 & 6888 \\
\hline $\begin{array}{l}8 / 2 / 80 \\
8 / 2 / 80\end{array}$ & $\begin{array}{l}0.0 \\
0.0\end{array}$ & $\begin{array}{l}0035 \\
0335\end{array}$ & $\begin{array}{l}-4733.97 \\
-4715.16\end{array}$ & $\begin{array}{l}-2439.16 \\
-254.98\end{array}$ & $\begin{array}{l}3587.7 \\
3608.4\end{array}$ & $\begin{array}{l}8.6 \\
8.5\end{array}$ & $\begin{array}{l}317 \\
317\end{array}$ & $\begin{array}{l}277882 \\
27572\end{array}$ \\
\hline
\end{tabular}


Table 1. (Continued).

\begin{tabular}{|c|c|c|c|c|c|c|c|c|}
\hline $\begin{array}{l}\text { Day/Month } \\
\text { Year }\end{array}$ & $\begin{array}{l}\text { Time } \\
\text { Zone }\end{array}$ & Time & $\begin{array}{l}\text { Latitude } \\
\left(^{\circ}\right) \text { (min.) }\end{array}$ & $\begin{array}{l}\text { Longitude } \\
\left({ }^{\circ}\right) \text { (min.) }\end{array}$ & Miles & Speed & $\begin{array}{l}\text { Heading } \\
\left({ }^{\circ}\right)\end{array}$ & $\begin{array}{c}\text { Regional } \\
\text { Magnetic Field } \\
\text { Value } \\
\text { (gammas) }\end{array}$ \\
\hline $8 / 2 / 80$ & 0.0 & 0635 & -4656.41 & $-25 \quad 30.20$ & 3629.8 & 8.7 & 316 & 27463 \\
\hline $8 / 2 / 80$ & 0.0 & 0725 & -4651.19 & $\begin{array}{lll}-25 & 37.57\end{array}$ & 3637.1 & 9.5 & 309 & 27433 \\
\hline $8 / 2 / 80$ & 0.0 & 0745 & -4649.20 & -2541.14 & 3640.2 & 8.8 & 314 & 27421 \\
\hline $8 / 2 / 80$ & 0.0 & 1045 & -4630.76 & $\begin{array}{ll}-26 & 8.81\end{array}$ & 3666.7 & 9.1 & 314 & 27315 \\
\hline $8 / 2 / 80$ & 0.0 & 1125 & -4626.50 & $-26 \quad 15.02$ & 3672.7 & 8.9 & 319 & 27290 \\
\hline $8 / 2 / 80$ & 0.0 & 1425 & $-46 \quad 6.08$ & -2640.15 & 3699.5 & 9.1 & 317 & 27176 \\
\hline $8 / 2 / 80$ & 0.0 & 1515 & $-46 \quad 0.46$ & $-26 \quad 47.47$ & 3707.1 & 9.8 & 315 & 27145 \\
\hline $8 / 2 / 80$ & 0.0 & 1735 & $-45 \quad 44.26$ & 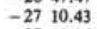 & 3729.9 & 3.9 & 308 & 27055 \\
\hline $8 / 2 / 80$ & 0.0 & 1745 & -4543.87 & -2711.16 & 3730.5 & 10.0 & 143 & 27052 \\
\hline $8 / 2 / 80$ & 0.0 & 1925 & -4557.26 & $-26 \quad 57.01$ & 3747.1 & 7.8 & 144 & 27124 \\
\hline $8 / 2 / 80$ & 0.0 & 1935 & $-45 \quad 58.32$ & -2655.93 & 3748.4 & 9.7 & 143 & 27130 \\
\hline $8 / 2 / 80$ & 0.0 & 2005 & $\begin{array}{lll}-46 & 2.21\end{array}$ & -2651.80 & 3753.3 & 3.6 & 144 & 27151 \\
\hline $8 / 2 / 80$ & 0.0 & 2015 & $\begin{array}{ll}-46 & 2.70\end{array}$ & -2651.30 & 3753.9 & 0.0 & 320 & 27154 \\
\hline $13 / 2 / 80$ & 0.0 & 0315 & $\begin{array}{lll}-46 & 1.88\end{array}$ & $-26 \quad 52.28$ & 3754.9 & 8.0 & 320 & 27148 \\
\hline $13 / 2 / 80$ & 0.0 & 0615 & $-45 \quad 43.47$ & -2714.51 & 3779.0 & 8.0 & 319 & 27047 \\
\hline $13 / 2 / 80$ & 0.0 & 0915 & $\begin{array}{rr}-45 & 25.06\end{array}$ & -2736.73 & 3803.1 & 8.2 & 320 & 26948 \\
\hline $13 / 2 / 80$ & 0.0 & 1055 & $-45 \quad 14.52$ & -2749.24 & 3816.8 & 8.7 & 320 & 26891 \\
\hline $13 / 2 / 80$ & 0.0 & 1355 & -4454.36 & $\begin{array}{lll}-28 & 12.91\end{array}$ & 3843.0 & 8.2 & 319 & 26785 \\
\hline $13 / 2 / 80$ & 0.0 & 1655 & -4435.72 & $-28 \quad 35.48$ & 3867.6 & 8.2 & 319 & 26687 \\
\hline $13 / 2 / 80$ & 0.0 & 1955 & -4417.08 & -2858.05 & 3892.2 & 8.2 & 319 & 26590 \\
\hline $13 / 2 / 80$ & 0.0 & 2255 & -4358.45 & $\begin{array}{l}-2920.62 \\
\end{array}$ & 3916.9 & 7.4 & 318 & 26495 \\
\hline $13 / 2 / 80$ & 0.0 & 2355 & $\begin{array}{lll}-43 & 52.87\end{array}$ & $\begin{array}{lll}-29 & 27.37\end{array}$ & 3924.3 & 8.2 & 327 & 26466 \\
\hline $14 / 2 / 80$ & 0.0 & 0025 & -4349.40 & $\begin{array}{l}-2930.44 \\
\end{array}$ & 3928.4 & 8.8 & 330 & 26450 \\
\hline $14 / 2 / 80$ & 0.0 & 0325 & -4326.29 & -2948.19 & 3954.9 & 9.2 & 330 & 26341 \\
\hline $14 / 2 / 80$ & 0.0 & 0625 & $\begin{array}{lll}-43 & 2.31\end{array}$ & $-30 \quad 6.95$ & 3982.5 & 8.5 & 327 & 26231 \\
\hline $14 / 2 / 80$ & 0.0 & 0645 & $\begin{array}{l}-4259.92 \\
\end{array}$ & $\begin{array}{r}-30 \\
-3.07\end{array}$ & 3985.3 & 8.5 & 323 & 26219 \\
\hline $14 / 2 / 80$ & 0.0 & 0745 & -4253.07 & -3015.92 & 3993.8 & 8.4 & 320 & 26187 \\
\hline $14 / 2 / 80$ & 0.0 & 0755 & -4252.00 & -3017.15 & 3995.2 & 8.3 & 315 & 26182 \\
\hline $14 / 2 / 80$ & 0.0 & 1055 & -4234.23 & $\begin{array}{l}-3040.63 \\
\end{array}$ & 4020.0 & 8.3 & 316 & 26095 \\
\hline $14 / 2 / 80$ & 0.0 & 1155 & -4228.25 & -3048.38 & 4028.3 & 8.4 & 321 & 26066 \\
\hline $14 / 2 / 80$ & 0.0 & 1455 & $-42 \quad 8.45$ & $\begin{array}{ll}-31 & 9.38\end{array}$ & 4053.4 & 8.5 & 323 & 25974 \\
\hline $14 / 2 / 80$ & 0.0 & 1755 & -4147.90 & -3129.52 & 4078.8 & 8.5 & 324 & 25882 \\
\hline $14 / 2 / 80$ & 0.0 & 2055 & $\begin{array}{lll}-41 & 27.23\end{array}$ & -3149.52 & 4104.3 & 8.5 & 324 & 25791 \\
\hline $14 / 2 / 80$ & 0.0 & 2325 & -4110.01 & $\begin{array}{ll}-32 & 6.19\end{array}$ & 4125.6 & 7.9 & 319 & 25717 \\
\hline $15 / 2 / 80$ & 0.0 & 0225 & -4052.12 & -3226.62 & 4149.3 & 7.5 & 320 & 25637 \\
\hline $15 / 2 / 80$ & 0.0 & 0515 & -4035.78 & $\begin{array}{r}-3244.48 \\
\end{array}$ & 4170.5 & 7.7 & 326 & 25567 \\
\hline $15 / 2 / 80$ & 0.0 & 0815 & -4016.61 & $\begin{array}{ll}-33 & 1.31\end{array}$ & 4193.5 & 7.7 & 326 & 25489 \\
\hline $15 / 2 / 80$ & 0.0 & 1035 & $-40 \quad 1.70$ & -3314.41 & 4211.5 & 8.9 & 325 & 25429 \\
\hline $15 / 2 / 80$ & 0.0 & 1255 & -3944.50 & -3329.68 & 4232.3 & 9.1 & 321 & 25361 \\
\hline $15 / 2 / 80$ & 0.0 & 1405 & -3936.19 & -3338.38 & 4243.0 & 9.0 & 317 & 25328 \\
\hline $15 / 2 / 80$ & 0.0 & 1555 & -3924.11 & $\begin{array}{r}-3352.85 \\
\end{array}$ & 4259.4 & 8.6 & 305 & 25277 \\
\hline $15 / 2 / 80$ & 0.0 & 1615 & -3922.45 & -3355.88 & 4262.3 & 8.7 & 319 & 25270 \\
\hline $15 / 2 / 80$ & 0.0 & 1635 & -3920.23 & $\begin{array}{r}-3358.33 \\
\end{array}$ & 4265.2 & 8.9 & 316 & 25261 \\
\hline $15 / 2 / 80$ & 0.0 & 1715 & $-39 \quad 15.98$ & $-34 \quad 3.64$ & 4271.1 & 8.0 & 321 & 25243 \\
\hline $15 / 2 / 80$ & 0.0 & 2015 & $\begin{array}{ll}-38 & 57.26\end{array}$ & -3422.80 & 4295.0 & 7.9 & 322 & 25170 \\
\hline $15 / 2 / 80$ & 0.0 & 2315 & -3838.44 & $-34 \quad 41.24$ & 4318.7 & 7.5 & 322 & 25098 \\
\hline $15 / 2 / 80$ & 0.0 & 2335 & $\begin{array}{l}-38 \quad 36.46 \\
\end{array}$ & -3443.18 & 4321.2 & 7.6 & 318 & 25090 \\
\hline $16 / 2 / 80$ & 0.0 & 0235 & $\begin{array}{ll}-38 & 19.56\end{array}$ & $-35 \quad 2.54$ & 4343.9 & 8.1 & 315 & 25025 \\
\hline $16 / 2 / 80$ & 0.0 & 0345 & $\begin{array}{rr}-38 & 12.89\end{array}$ & $-35 \quad 11.03$ & 4353.3 & 8.7 & 312 & 24998 \\
\hline $16 / 2 / 80$ & 0.0 & 0415 & $-38 \quad 9.94$ & $-35 \quad 15.09$ & 4357.7 & 8.7 & 309 & 24986 \\
\hline $16 / 2 / 80$ & 0.0 & 0715 & -3753.18 & -3540.67 & 4383.9 & 8.8 & 310 & 24915 \\
\hline
\end{tabular}

Table 1. (Continued).

\begin{tabular}{|c|c|c|c|c|c|c|c|c|}
\hline $\begin{array}{l}\text { Day/Month } \\
\text { Year }\end{array}$ & $\begin{array}{l}\text { Time } \\
\text { Zone }\end{array}$ & Time & $\begin{array}{c}\text { Latitude } \\
\left({ }^{\circ}\right) \text { (min.) }\end{array}$ & $\begin{array}{l}\text { Longitude } \\
\text { ( }{ }^{\circ} \text { (min.) }\end{array}$ & Miles & Speed & $\begin{array}{c}\text { Heading } \\
\left({ }^{\circ}\right)\end{array}$ & $\begin{array}{c}\text { Regional } \\
\text { Magnetic Field } \\
\text { Value } \\
\text { (gammas) }\end{array}$ \\
\hline $16 / 2 / 80$ & 0.0 & 0755 & -3749.40 & -3546.36 & 4389.8 & 9.3 & 305 & 24900 \\
\hline $16 / 2 / 80$ & 0.0 & 0845 & -3744.86 & -3554.32 & 4397.5 & 9.2 & 316 & 24880 \\
\hline $16 / 2 / 80$ & 0.0 & 0855 & -3743.73 & -3555.65 & 4399.1 & 9.3 & 324 & 24876 \\
\hline $16 / 2 / 80$ & 0.0 & 0925 & -3739.95 & -3559.08 & 4403.7 & 7.7 & 324 & 24862 \\
\hline $16 / 2 / 80$ & 0.0 & 0945 & $\begin{array}{lll}-37 & 37.87\end{array}$ & -360.95 & 4406.3 & 9.0 & 323 & 24855 \\
\hline $16 / 2 / 80$ & 0.0 & 1245 & -3716.03 & $\begin{array}{lll}-36 & 21.22\end{array}$ & 4433.4 & 8.6 & 322 & 24779 \\
\hline $16 / 2 / 80$ & 0.0 & 1305 & $\begin{array}{l}-37 \\
-33.75\end{array}$ & $\begin{array}{ll}-36 & 23.39\end{array}$ & 4436,3 & 8.4 & 325 & 24772 \\
\hline $16 / 2 / 80$ & 0.0 & 1315 & $-37 \quad 12.60$ & -3624.38 & 4437.6 & 8.3 & 330 & 24768 \\
\hline $16 / 2 / 80$ & 0.0 & 1325 & $-37 \quad 11.39$ & $\begin{array}{lll}-36 & 25.24\end{array}$ & 4439.0 & 8.1 & 336 & 24764 \\
\hline $16 / 2 / 80$ & 0.0 & 1625 & -3649.17 & -3637.60 & 4463.4 & 7.9 & 337 & 24698 \\
\hline $16 / 2 / 80$ & 0.0 & 1635 & $-36 \quad 47.96$ & -3638.24 & 4464.7 & 7.8 & 333 & 24694 \\
\hline $16 / 2 / 80$ & 0.0 & 1645 & -3646.80 & -3638.97 & 4466.0 & 8.1 & 328 & 24691 \\
\hline $16 / 2 / 80$ & 0.0 & 1945 & $\begin{array}{l}-36 \quad 26.19 \\
\end{array}$ & $-36 \$ 4.95$ & 4490.2 & 9.3 & 325 & 24626 \\
\hline $16 / 2 / 80$ & 0.0 & 2245 & $\begin{array}{ll}-36 & 3.13\end{array}$ & -3714.57 & 4518.2 & 9.4 & 325 & 24554 \\
\hline $17 / 2 / 80$ & 0.0 & 0145 & -3540.03 & $\begin{array}{l}-3734.28 \\
\end{array}$ & 4546.3 & 9.1 & 324 & 24484 \\
\hline $17 / 2 / 80$ & 0.0 & 0445 & -3517.76 & -3753.50 & 4573.5 & 8.6 & 330 & 24418 \\
\hline $17 / 2 / 80$ & 0.0 & 0745 & $-34 \quad 55.34$ & -389.18 & 4599.3 & 8.6 & 330 & 24358 \\
\hline $17 / 2 / 80$ & 0.0 & 0945 & -3440.27 & -3819.46 & 4616.6 & 8.5 & 327 & 24319 \\
\hline $17 / 2 / 80$ & 0.0 & 1245 & -3418.82 & $\begin{array}{r}-3835.89 \\
\end{array}$ & 4642.0 & 8.2 & 326 & 24263 \\
\hline $17 / 2 / 80$ & 0.0 & 1455 & $-34 \quad 3.94$ & $\begin{array}{r}-3847.83 \\
\end{array}$ & 4659.8 & 8.0 & 327 & 24225 \\
\hline $17 / 2 / 80$ & 0.0 & 1645 & -3351.46 & $\begin{array}{l}-3857.29 \\
\end{array}$ & 4674.6 & 9.2 & 329 & 24194 \\
\hline $17 / 2 / 80$ & 0.0 & 1945 & $\begin{array}{ll}-33 & 27.72\end{array}$ & $\begin{array}{lll}-39 & 13.90\end{array}$ & 4702.1 & 9.2 & 329 & 24138 \\
\hline $17 / 2 / 80$ & 0.0 & 2105 & -3317.16 & -3921.31 & 4714.3 & 9.8 & 324 & 24114 \\
\hline $18 / 2 / 80$ & 0.0 & 0005 & -3253.06 & -3941.68 & 4743.8 & 9.7 & 323 & 24057 \\
\hline $18 / 2 / 80$ & 0.0 & 0215 & $-32 \quad 36.32$ & $\begin{array}{l}-3956.58 \\
\end{array}$ & 4764.7 & 9.1 & 318 & 24017 \\
\hline $18 / 2 / 80$ & 0.0 & 0405 & -3223.74 & $-40 \quad 9.71$ & 4781.5 & 9.0 & 323 & 23987 \\
\hline $18 / 2 / 80$ & 0.0 & 0425 & -3221.32 & $-40 \quad 11.81$ & 4784.5 & 8.9 & 329 & 23981 \\
\hline $18 / 2 / 80$ & 0.0 & 0435 & -3220.04 & $\begin{array}{ll}-40 & 12.72\end{array}$ & 4786.0 & 9.0 & 334 & 23979 \\
\hline $18 / 2 / 80$ & 0.0 & 0615 & $\begin{array}{lll}-32 & 6.47\end{array}$ & $\begin{array}{ll}-40 & 20.33\end{array}$ & 4801,0 & 9.4 & 338 & 23953 \\
\hline $18 / 2 / 80$ & 0.0 & 0805 & $\begin{array}{lll}-31 & 50.48\end{array}$ & -4027.89 & 4818.2 & 9.7 & 333 & 23926 \\
\hline $18 / 2 / 80$ & 0.0 & 1055 & $\begin{array}{lll}-31 & 25.81\end{array}$ & -4042.16 & 4845.7 & 9.5 & 329 & 23883 \\
\hline $18 / 2 / 80$ & 0.0 & 1355 & $-31 \quad 1.15$ & $\begin{array}{r}-4059.18 \\
\end{array}$ & 4874.4 & 9.2 & 331 & 23840 \\
\hline $18 / 2 / 80$ & 0.0 & 1455 & $\begin{array}{lll}-30 & 53.07\end{array}$ & $\begin{array}{lll}-41 & 4.25\end{array}$ & 4883.5 & 6.3 & 331 & 23827 \\
\hline $18 / 2 / 80$ & 0.0 & 1505 & $-30 \quad 52.15$ & $\begin{array}{lll}-41 & 4.84\end{array}$ & 4884.6 & 8.4 & 330 & 23825 \\
\hline $18 / 2 / 80$ & 0.0 & 1805 & $\begin{array}{ll}-30 & 30.37\end{array}$ & $-41 \quad 19.39$ & 4909.7 & 8.8 & 326 & 23790 \\
\hline $18 / 2 / 80$ & 0.0 & 2035 & $\begin{array}{lll}-30 & 12.01\end{array}$ & -4133.56 & 4931.8 & 8.5 & 321 & 23760 \\
\hline $18 / 2 / 80$ & 0.0 & 2335 & $\begin{array}{r}-2952.06 \\
\end{array}$ & $\begin{array}{r}-4151.76 \\
-120\end{array}$ & 4957.2 & 8.4 & 321 & 23726 \\
\hline $19 / 2 / 80$ & 0.0 & 0215 & -2934.42 & $\begin{array}{r}-42 \quad 7.78 \\
\end{array}$ & 4979.7 & 6.8 & 319 & 23698 \\
\hline $19 / 2 / 80$ & 0.0 & 0515 & $\begin{array}{lll}-29 & 18.73\end{array}$ & $\begin{array}{ll}-42 & 23.02\end{array}$ & 5000.2 & 6.4 & 325 & 23672 \\
\hline $19 / 2 / 80$ & 0.0 & 0645 & $\begin{array}{lll}-29 & 10.88\end{array}$ & -4229.29 & 5009.8 & 8.4 & 323 & 23662 \\
\hline $19 / 2 / 80$ & 0.0 & 0945 & $-28 \quad 50.73$ & $-42 \quad 46.34$ & 5034.9 & 8.5 & 322 & 23634 \\
\hline $19 / 2 / 80$ & 0.0 & 1125 & $-28 \quad 39.50$ & $\begin{array}{l}-42 \quad 56.19 \\
\end{array}$ & 5049.0 & 8.5 & 332 & 23619 \\
\hline $19 / 2 / 80$ & 0.0 & 1145 & -2836.97 & -4257.68 & 5051.9 & 7.2 & 332 & 23617 \\
\hline $19 / 2 / 80$ & 0.0 & 1445 & $\begin{array}{lll}-28 & 17.87\end{array}$ & $\begin{array}{lll}-43 & 8.84\end{array}$ & 5073.3 & 7.0 & 332 & 23598 \\
\hline $19 / 2 / 80$ & 0.0 & 1655 & $\begin{array}{ll}-28 & 4.49\end{array}$ & -4316.75 & 5088.4 & 6.8 & 336 & 23586 \\
\hline $19 / 2 / 80$ & 0.0 & 1955 & $-27 \quad 45.77$ & $\begin{array}{l}-4325.89 \\
\end{array}$ & 5108.8 & 6.8 & 336 & 23572 \\
\hline $19 / 2 / 80$ & 0.0 & 2105 & -2738.50 & -4329.45 & 5116.7 & 6.8 & 341 & 23568 \\
\hline $19 / 2 / 80$ & 0.0 & 2205 & -2732.08 & -4331.87 & 5123.5 & 6.7 & 335 & 23564 \\
\hline $20 / 2 / 80$ & 0.0 & 0105 & -2714.00 & -4341.37 & 5143.5 & 6.6 & 334 & 23553 \\
\hline $20 / 2 / 80$ & 0.0 & 0155 & -279.00 & -4344.03 & 5149.0 & & & 23550 \\
\hline
\end{tabular}




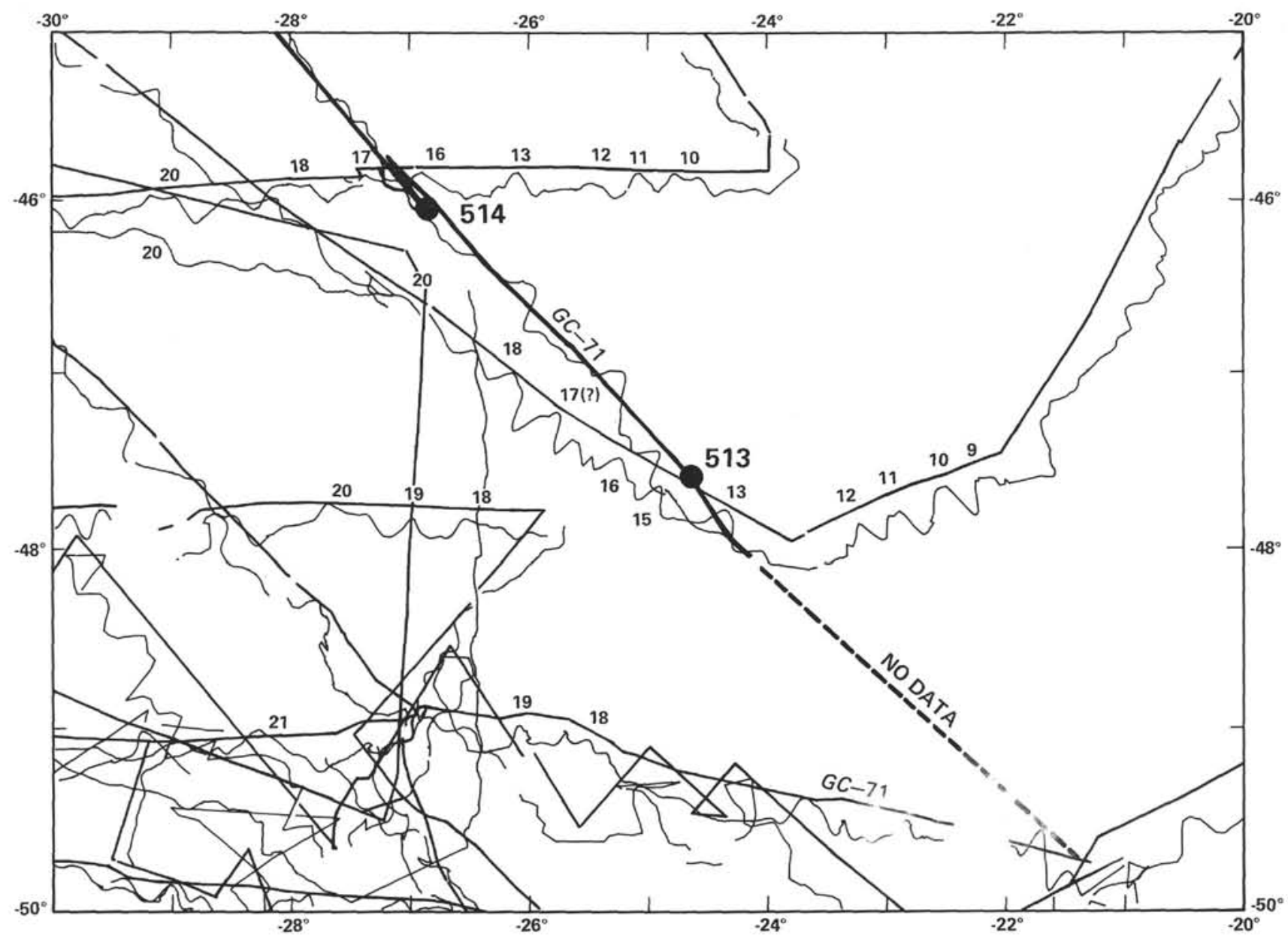

Figure 3. Magnetic anomalies plotted normal to ship's track in the vicinity of Sites 513 and 514 . Magnetic anomaly identification after Heirtzler et al. (1968) and LaBrecque et al. (1977). 


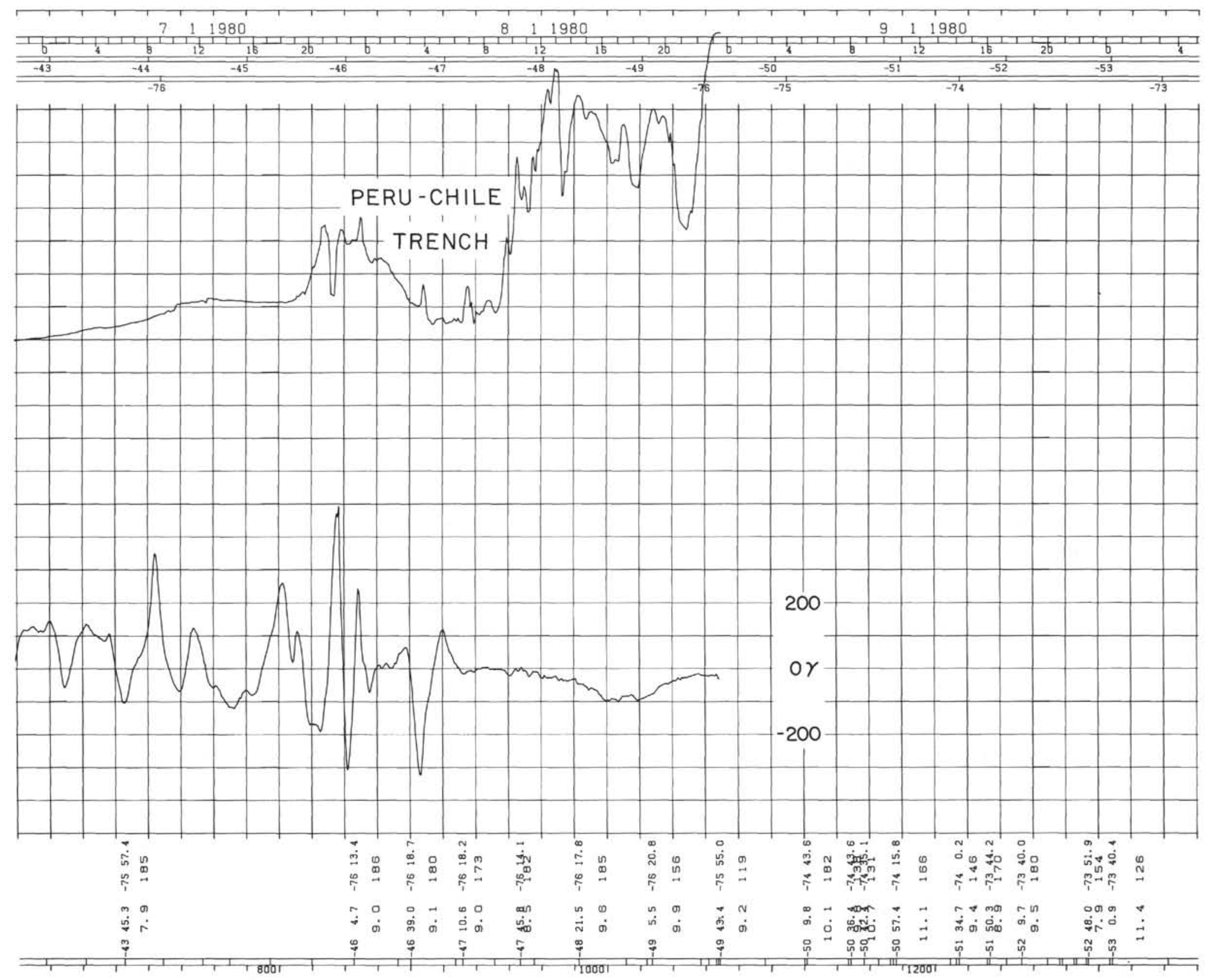




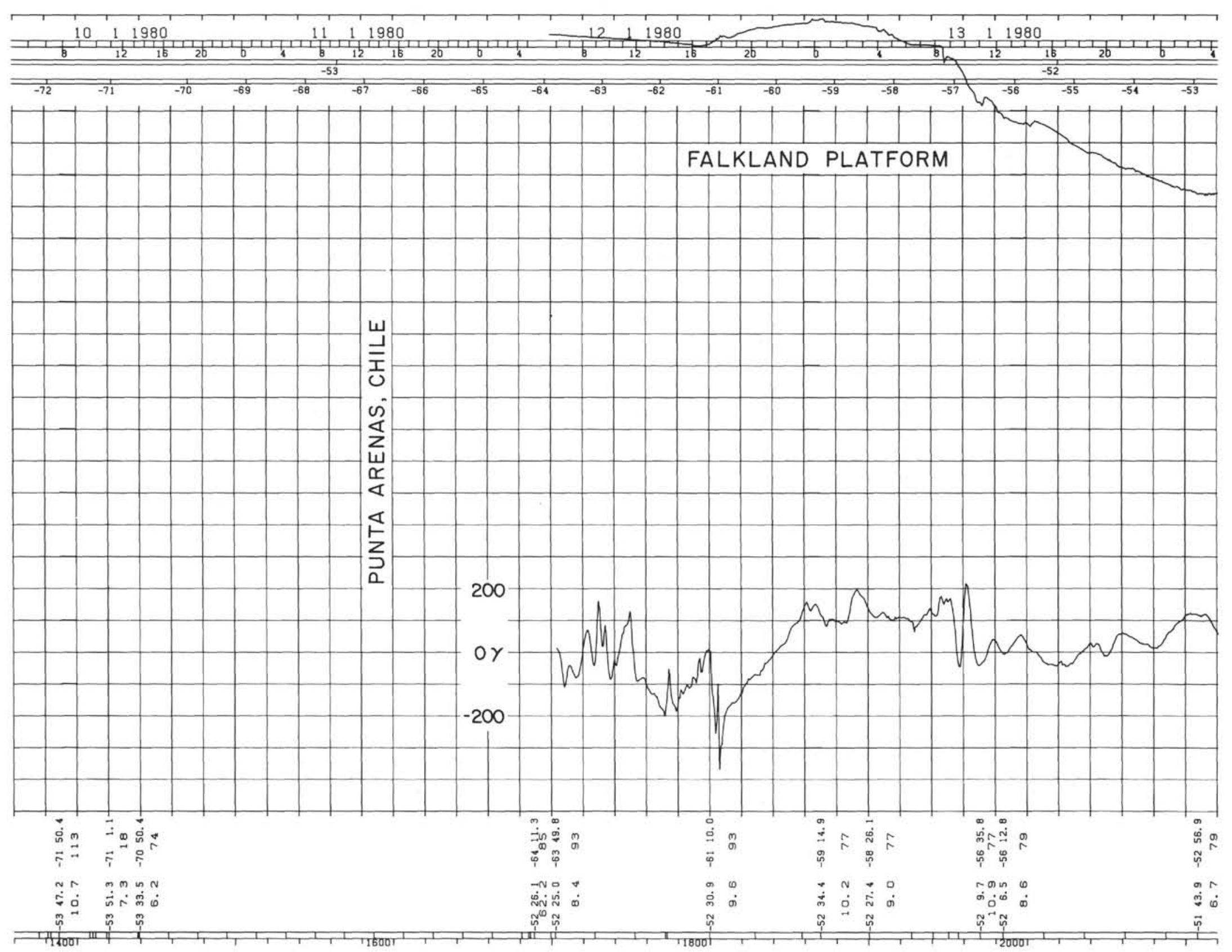




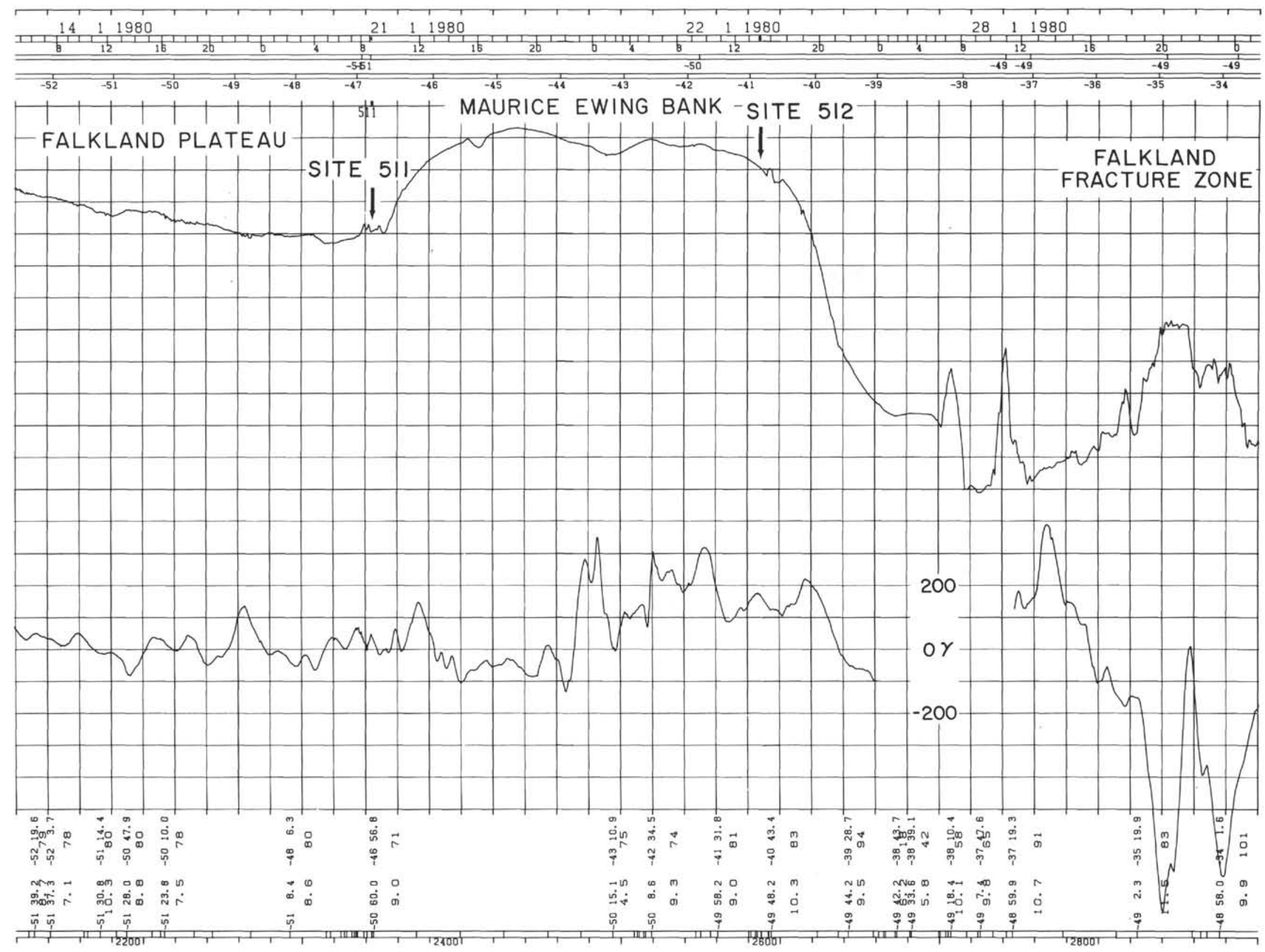




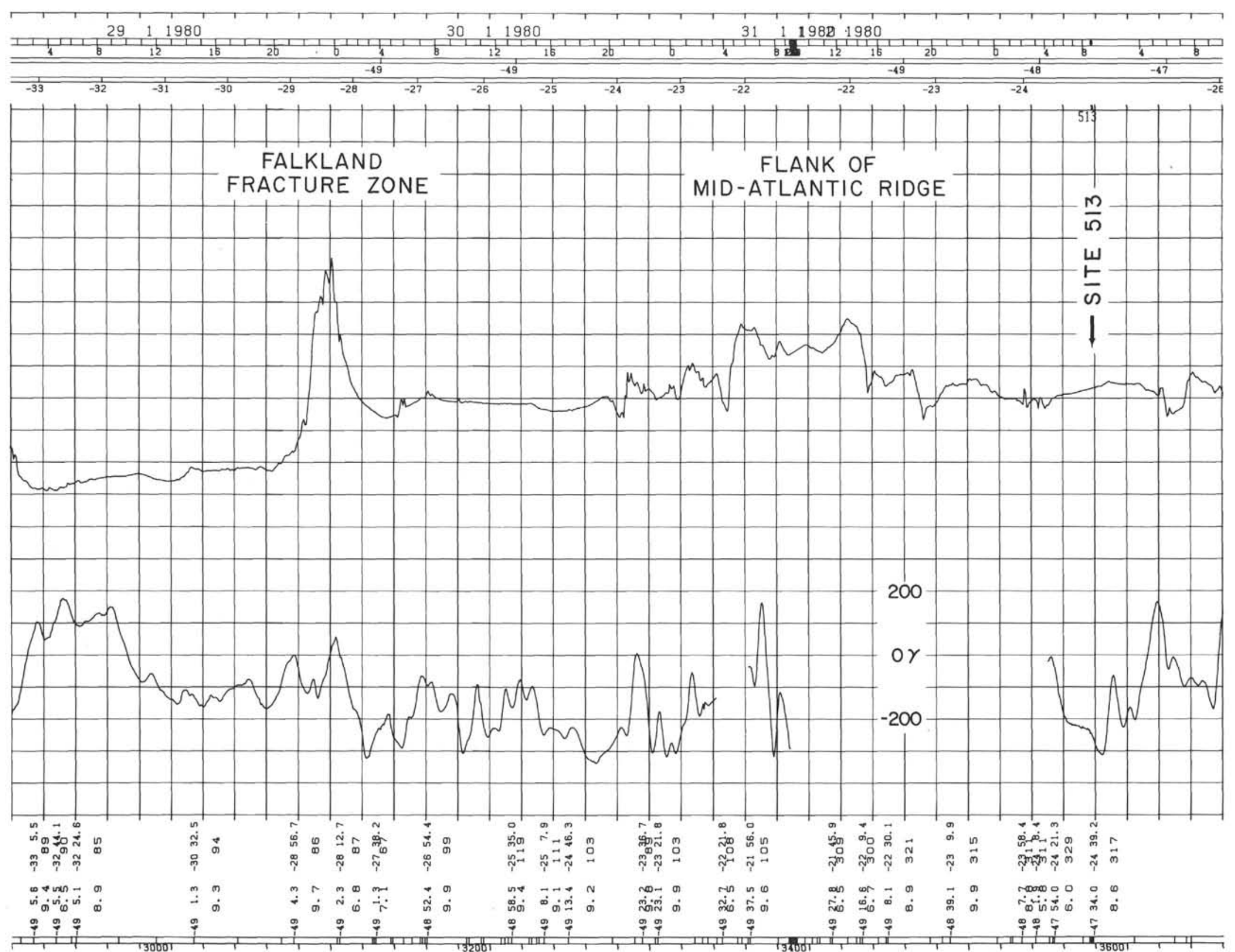




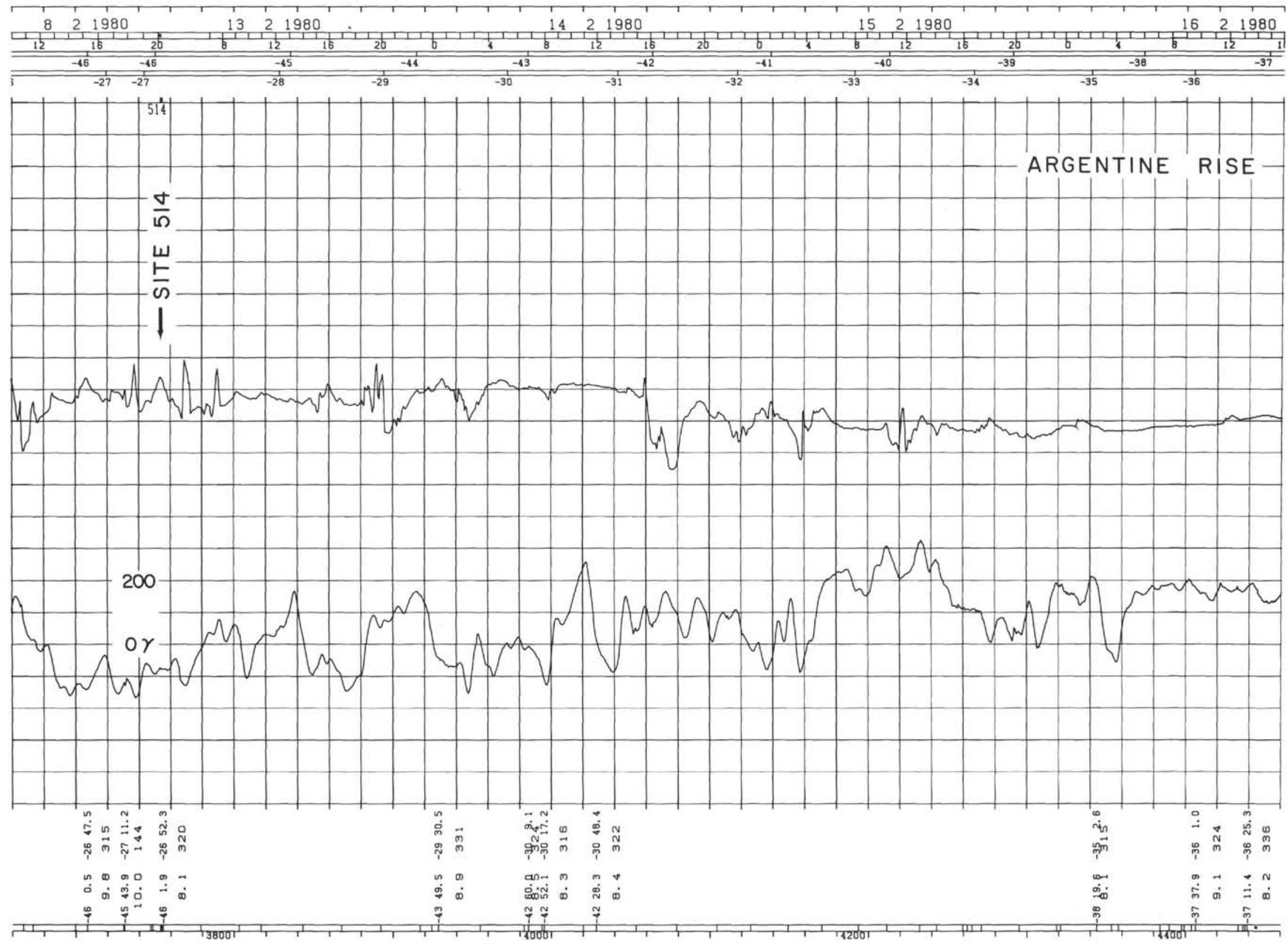

สิ Figure 4. (Continued). 


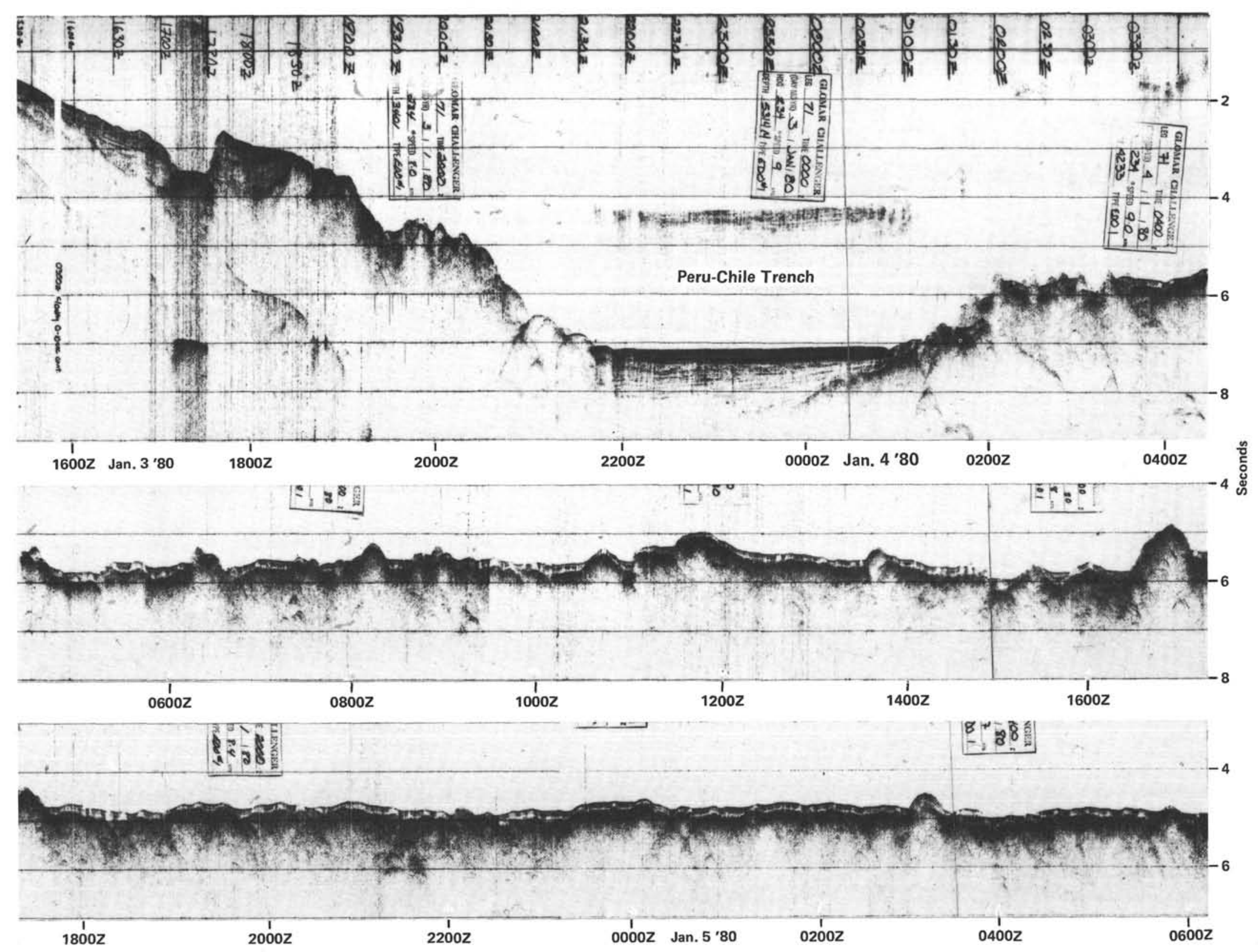

Figure 5. Seismic reflection profiles along track of Leg 71 of Glomar Challenger. 


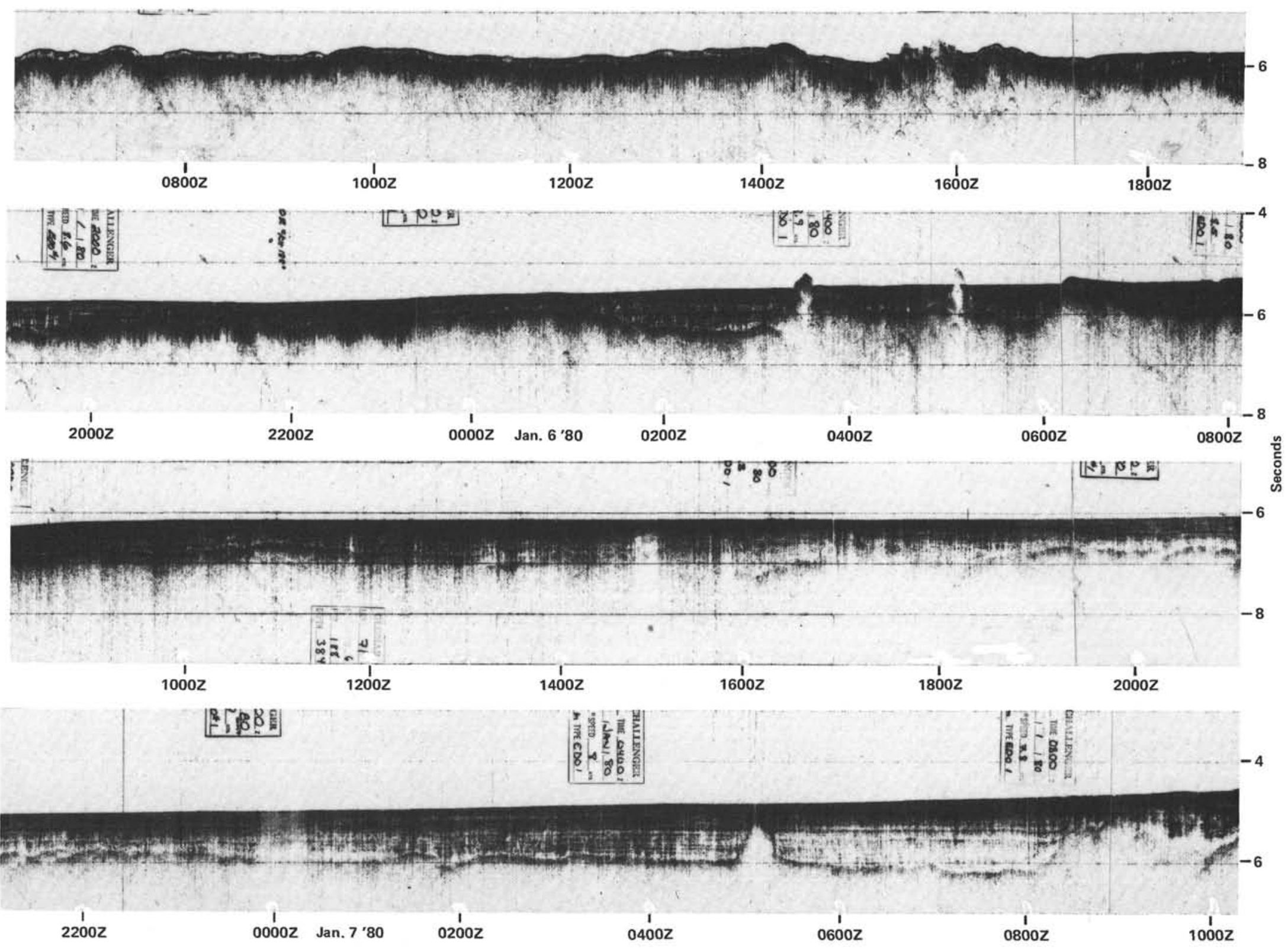



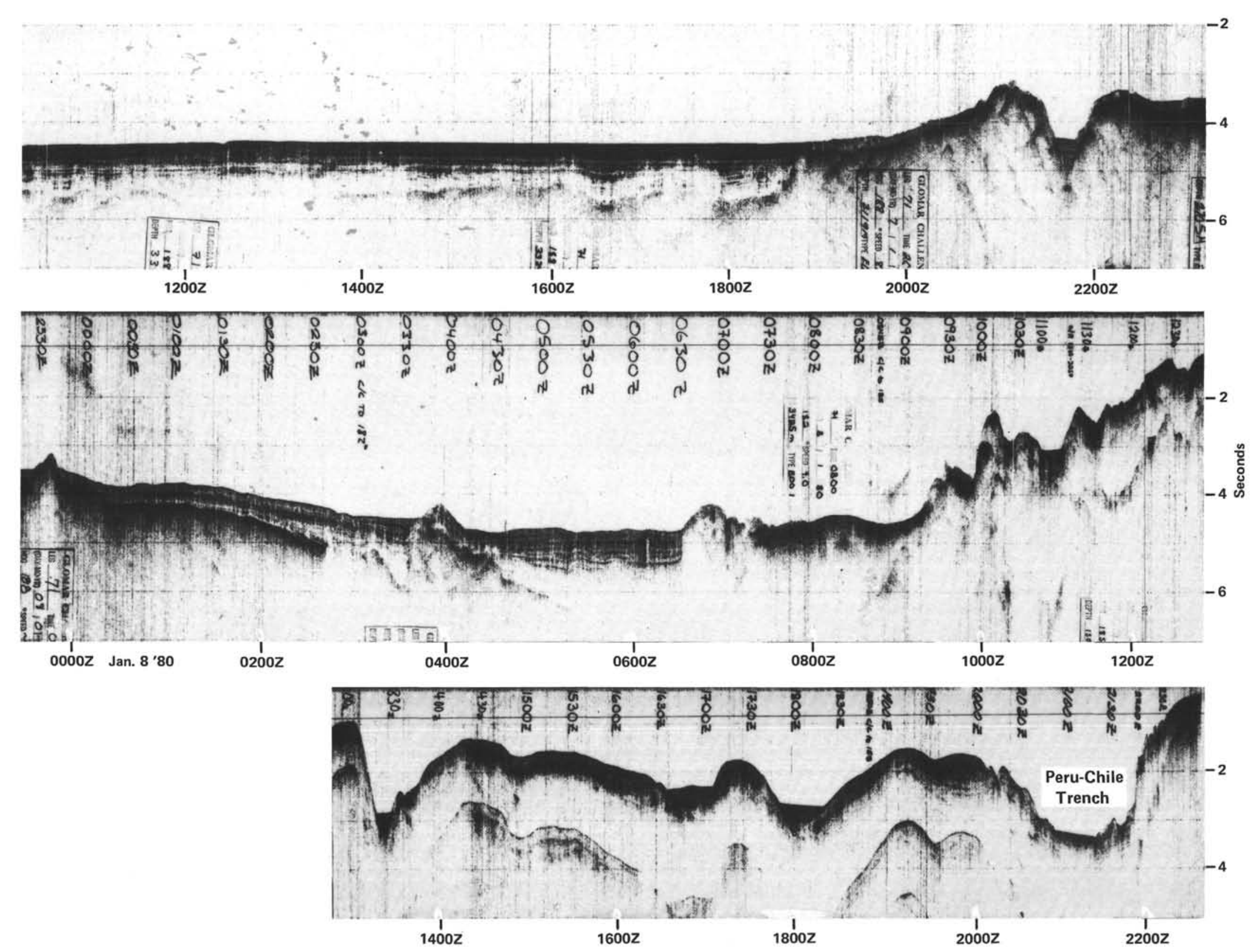

Figure 5. (Continued). 


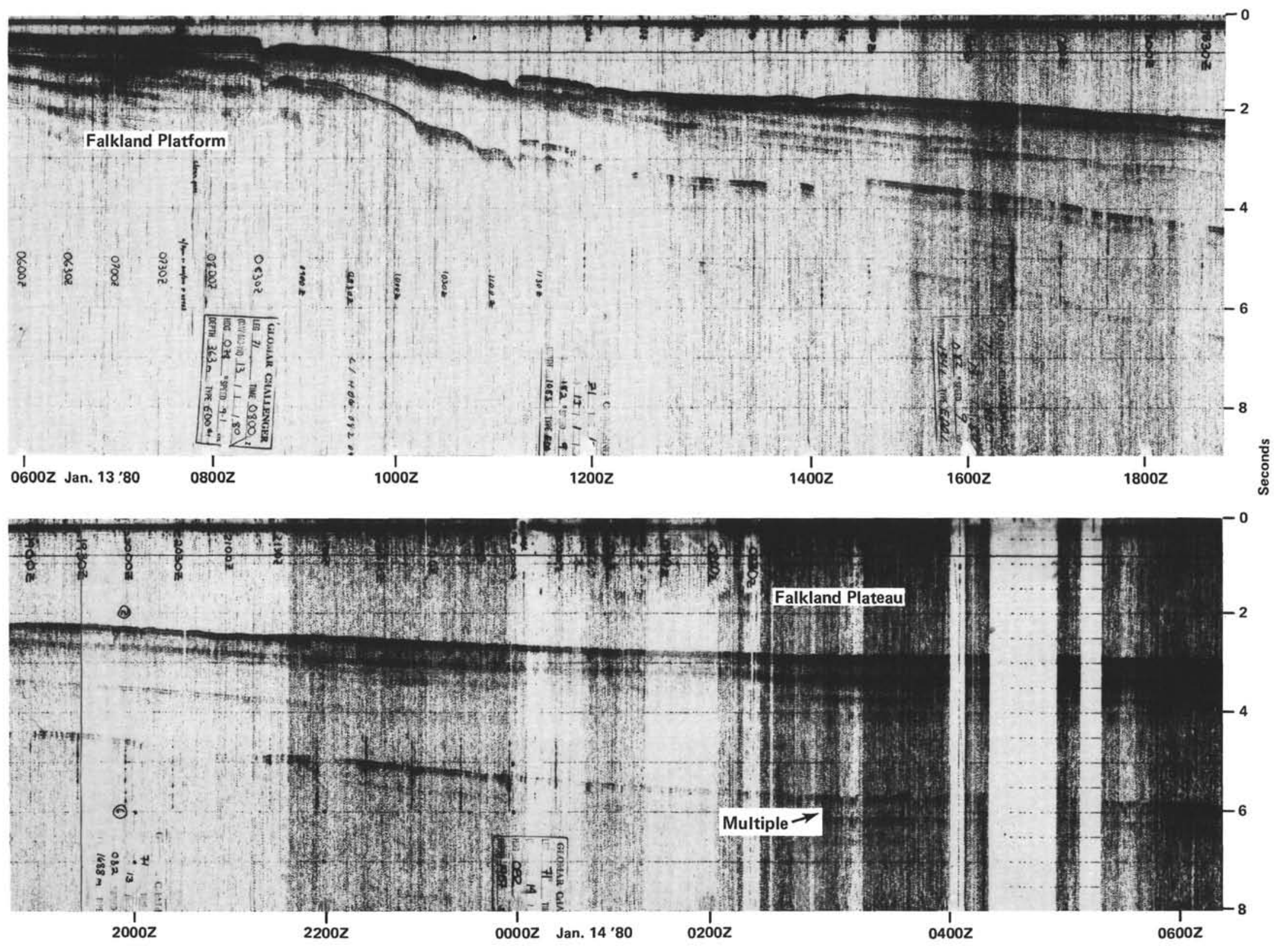




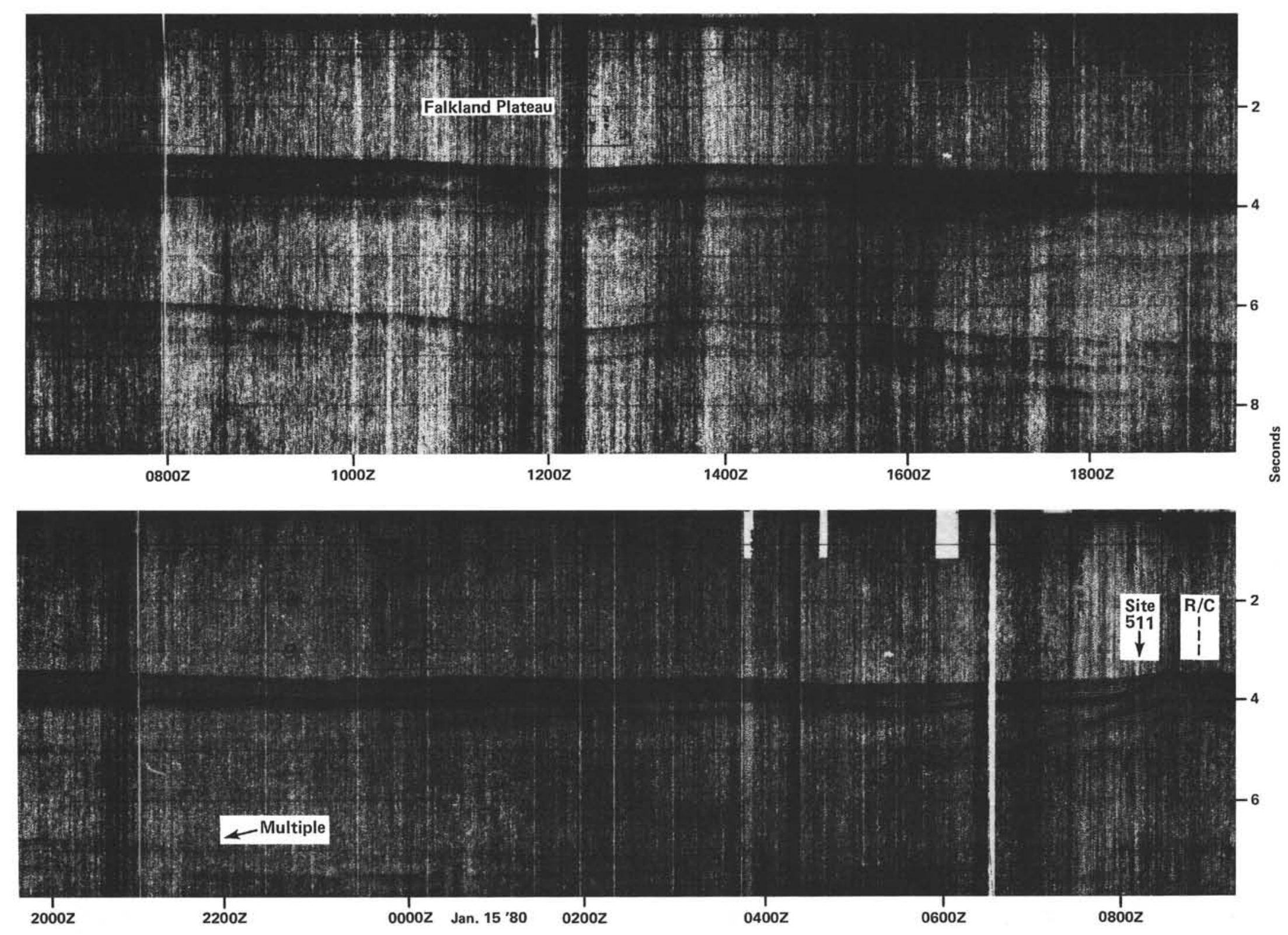

Figure 5. (Continued). 

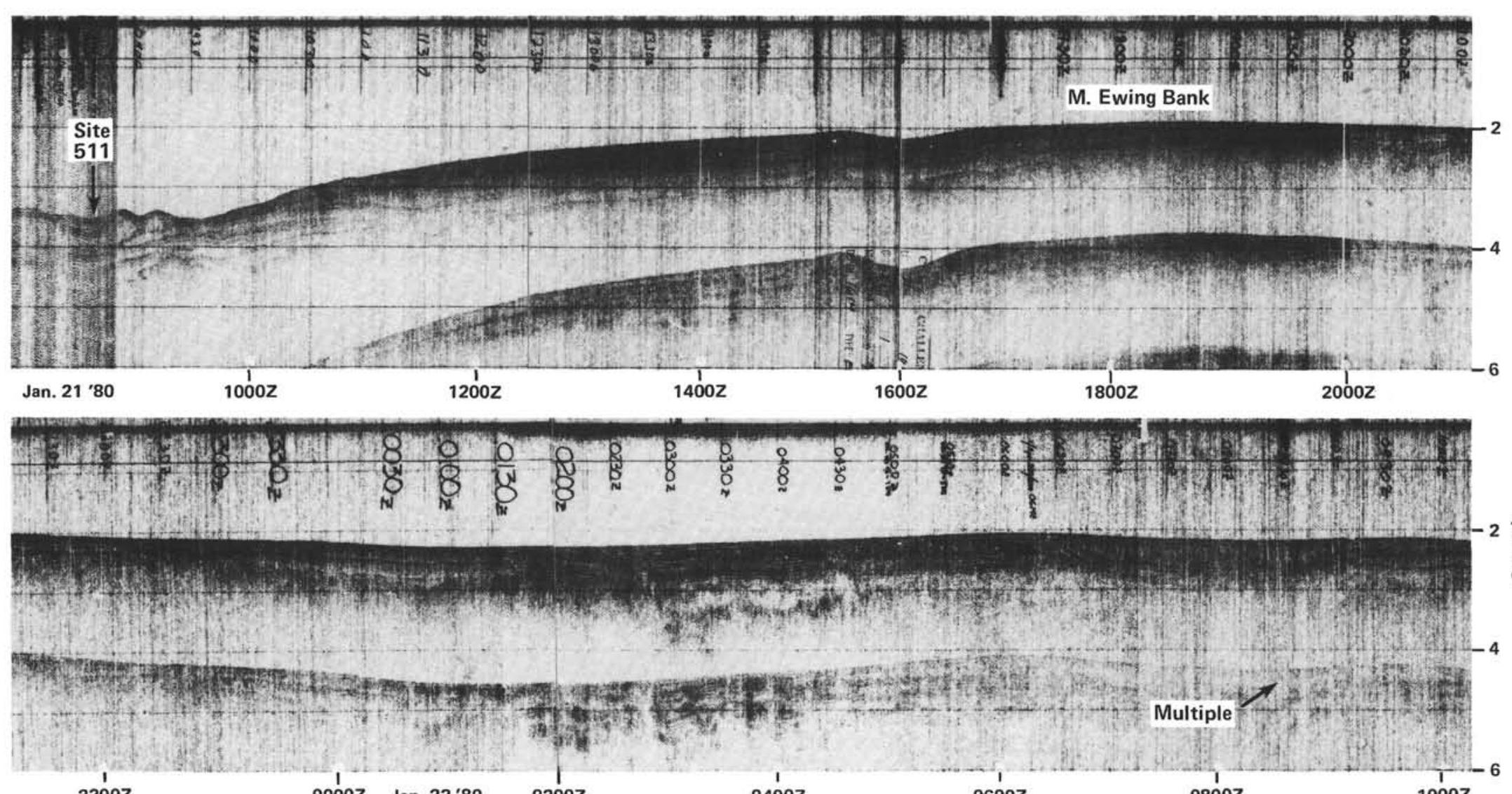

$2200 z$

$0000 Z$ Jan. 22'80 $0200 Z$

if
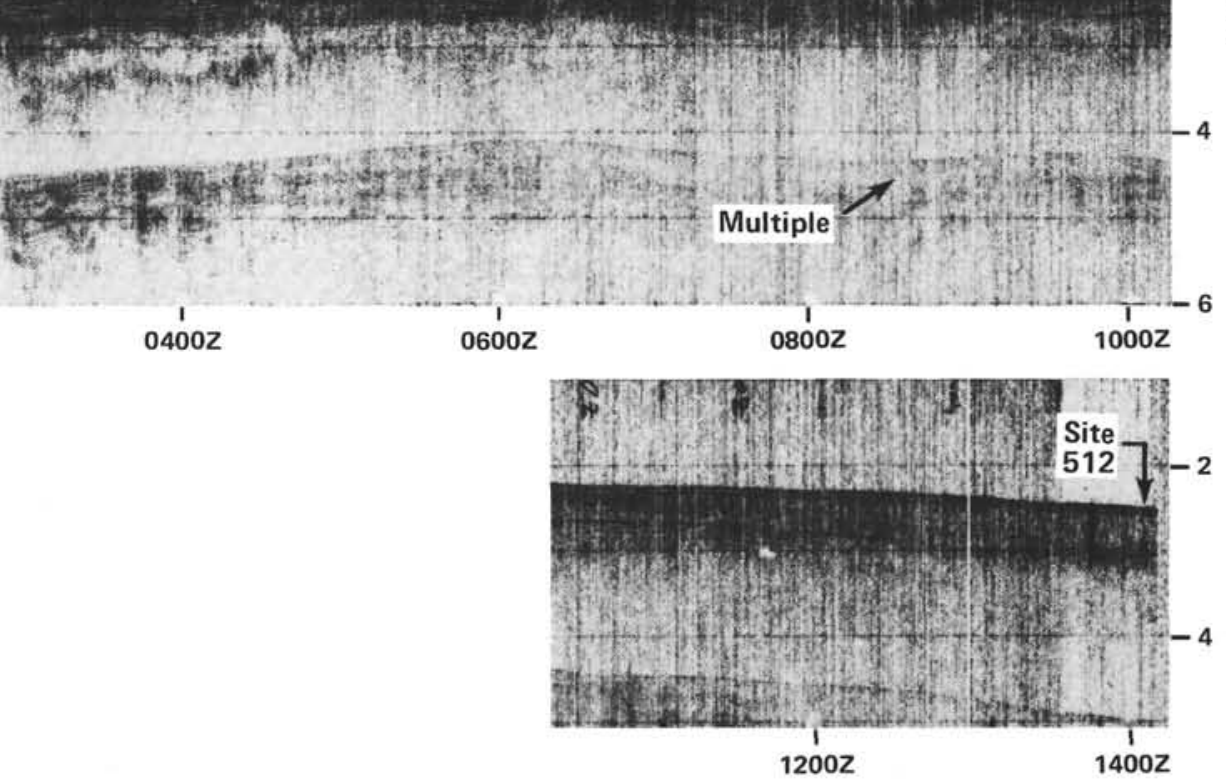

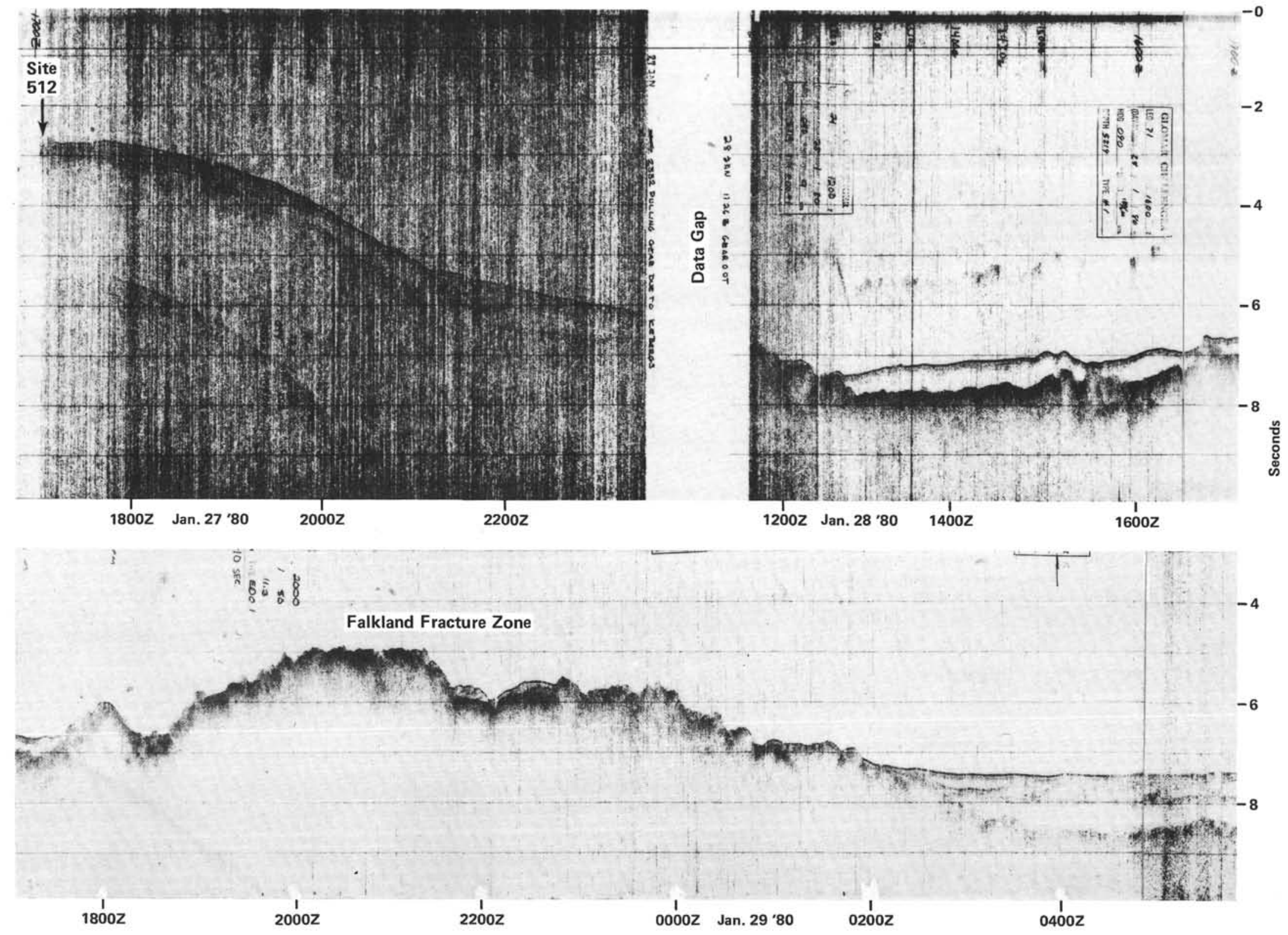

Figure 5. (Continued). 


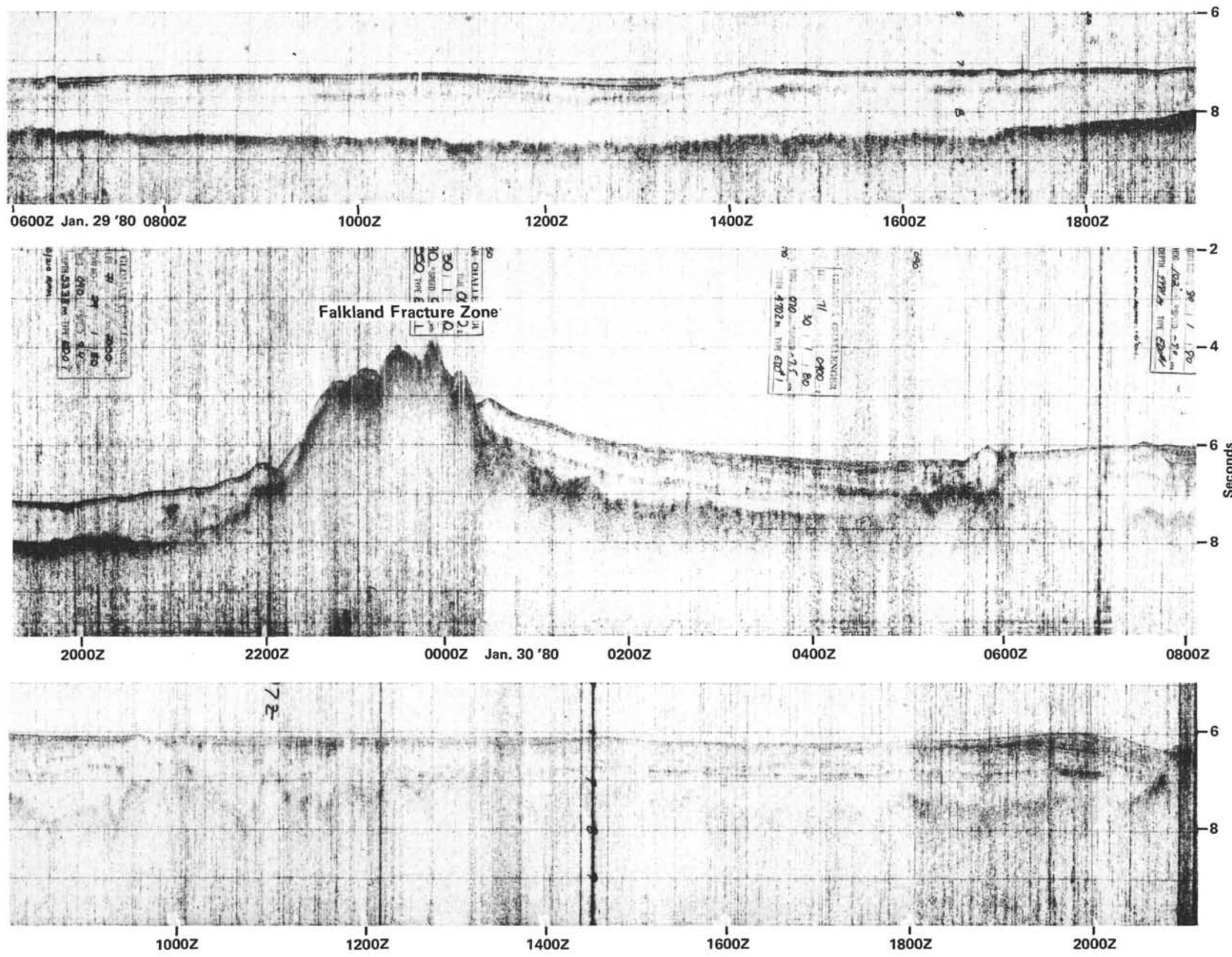



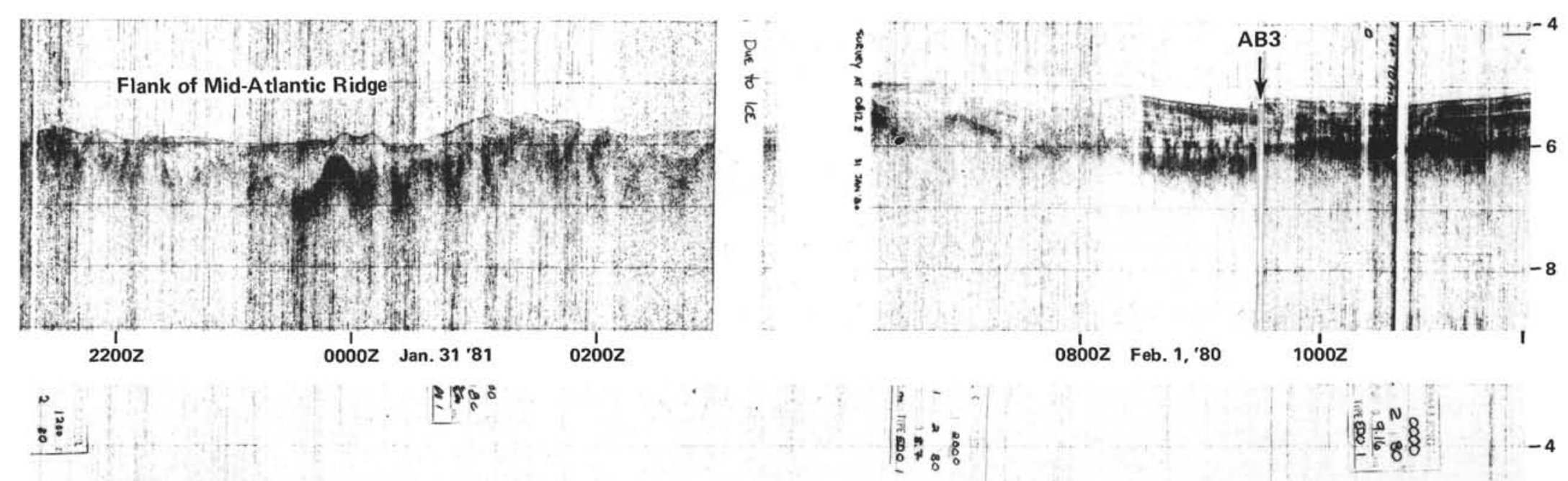

202 Feb. 1, 80

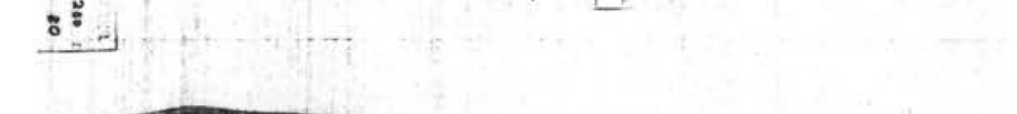

in th
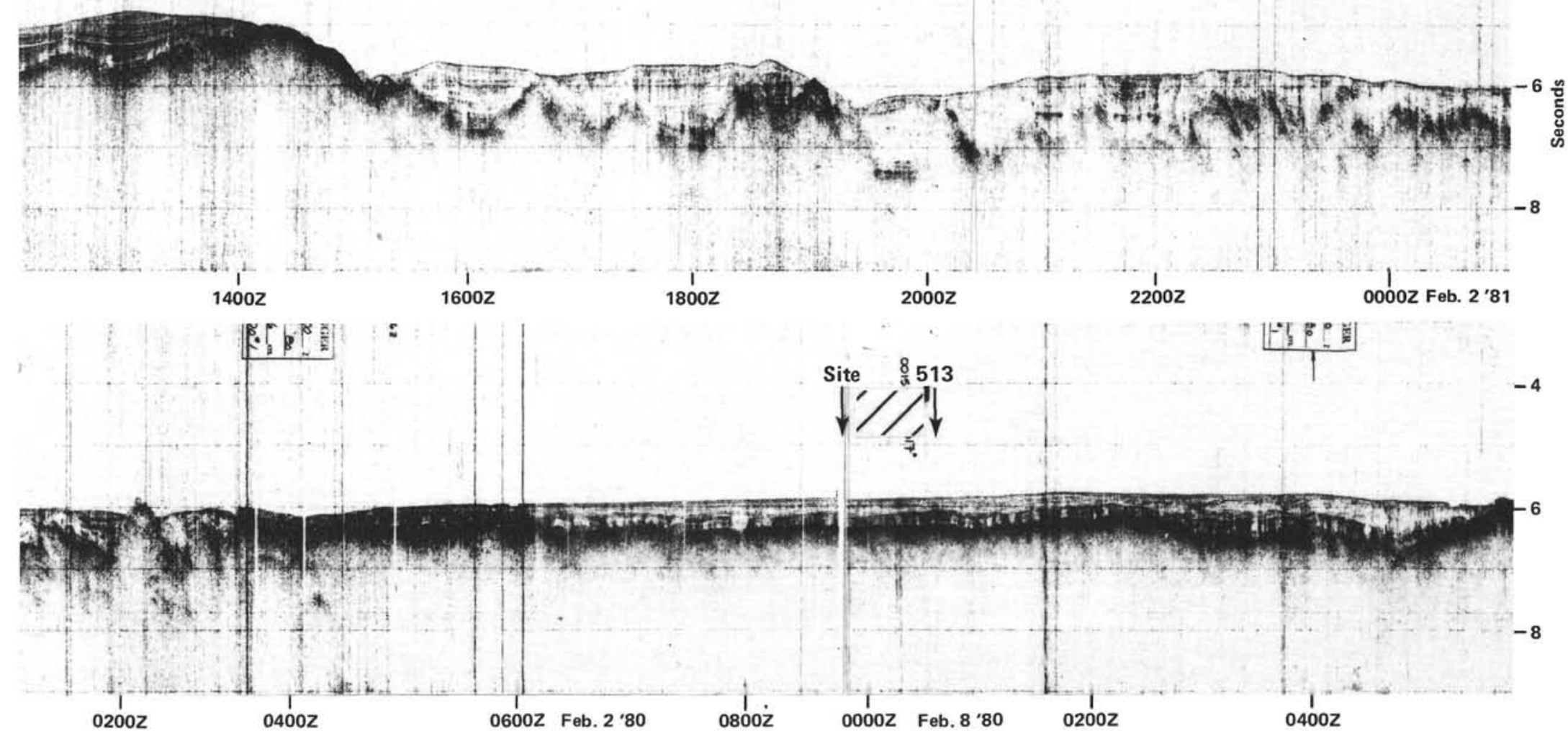


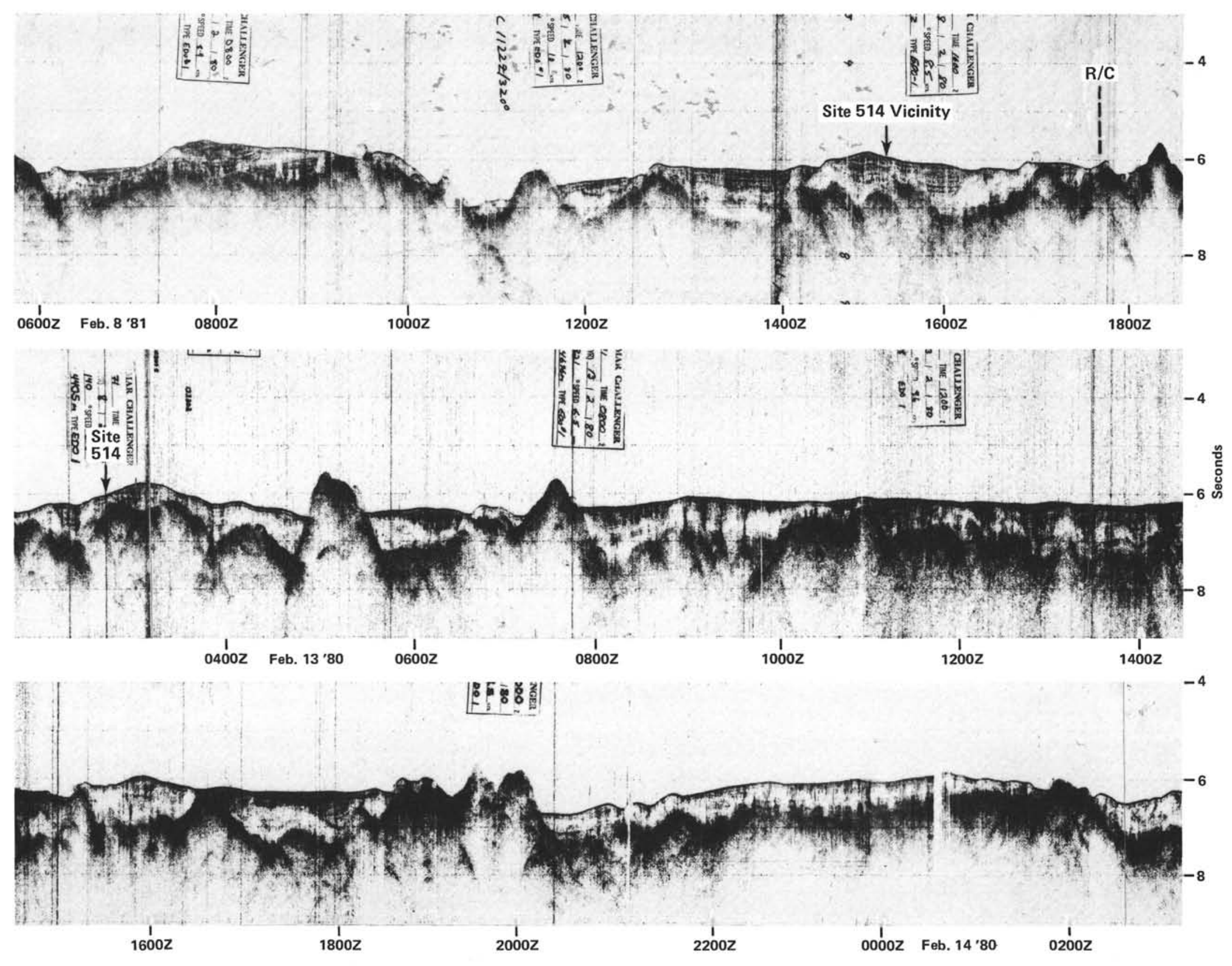




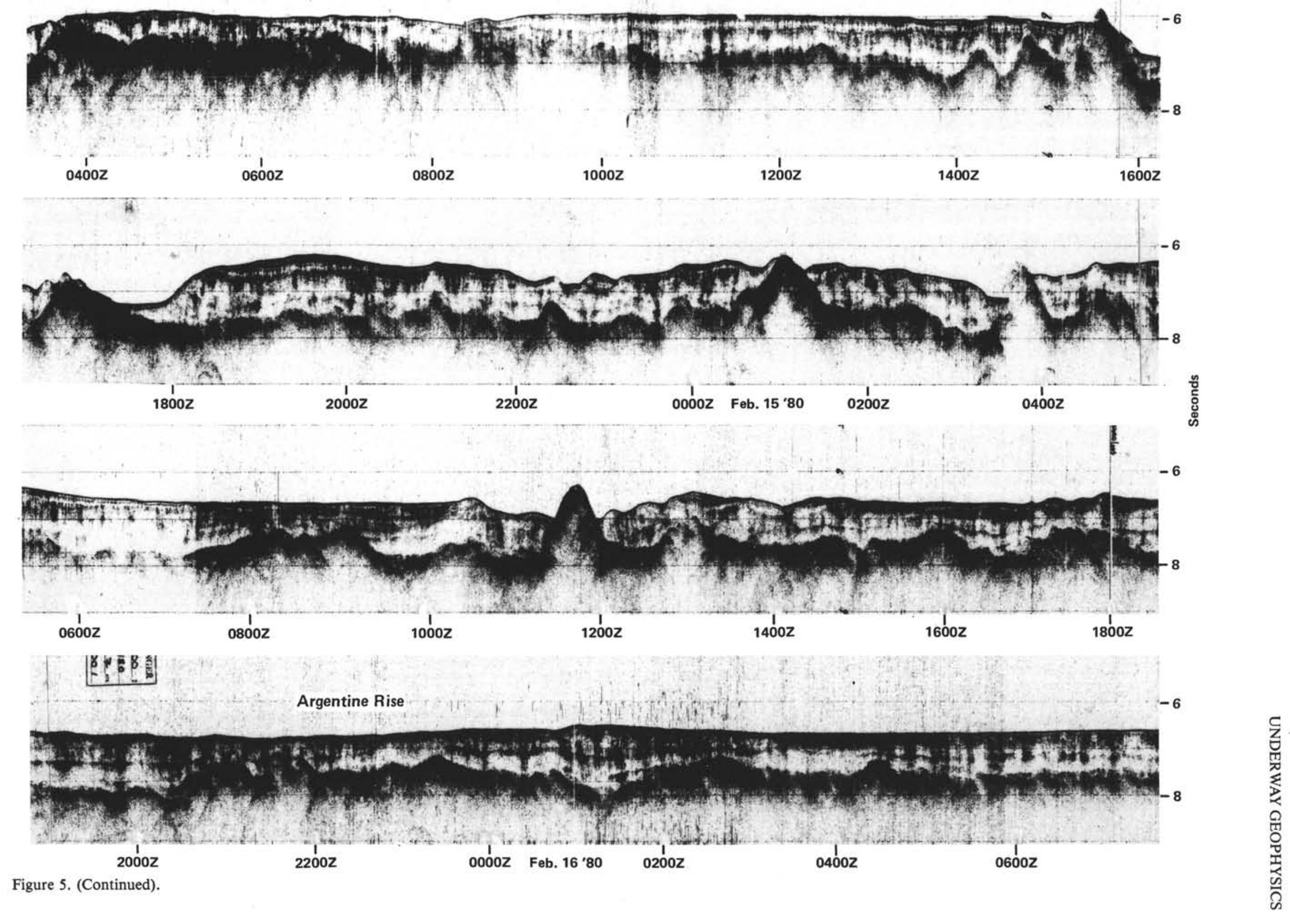



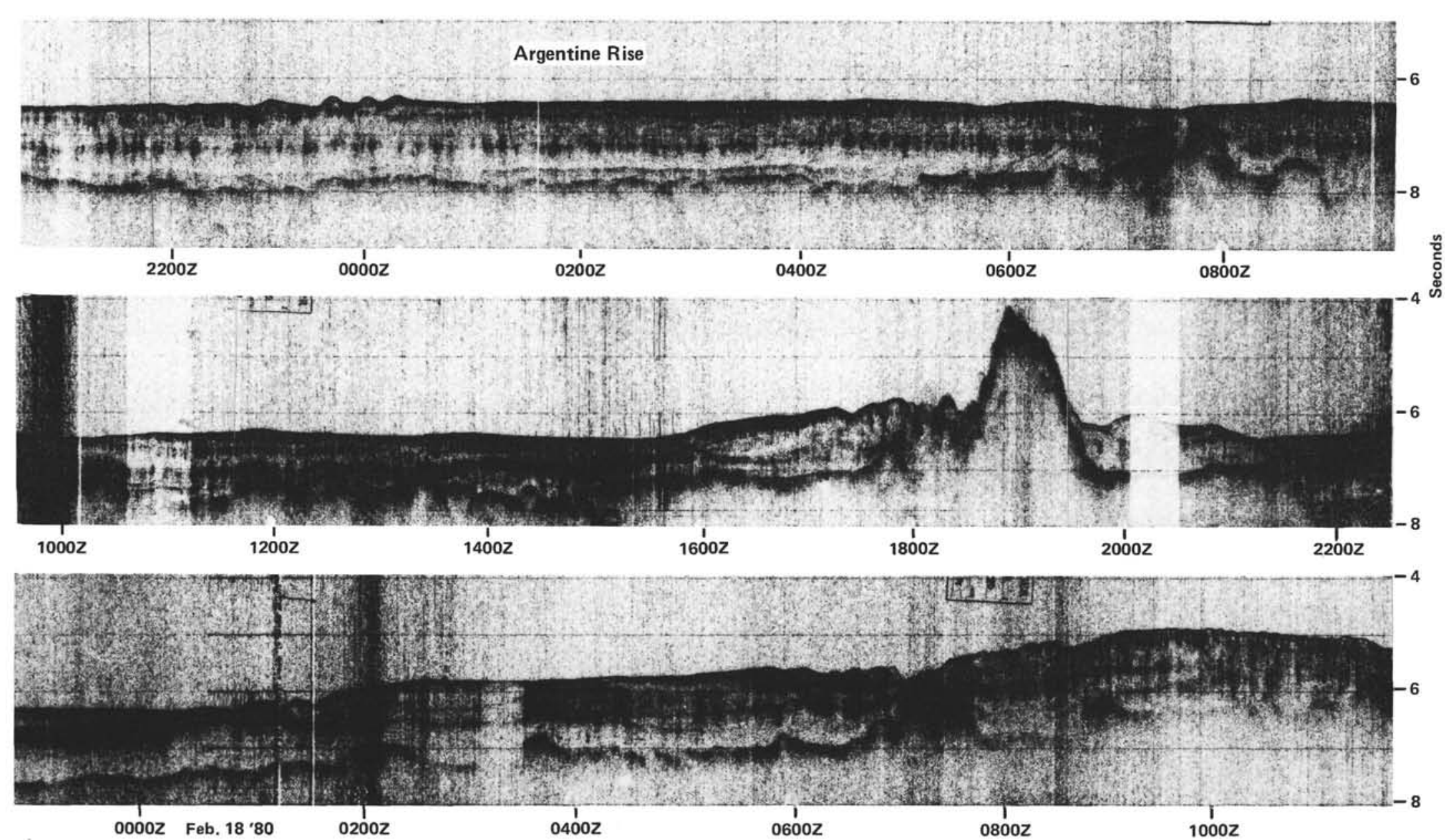


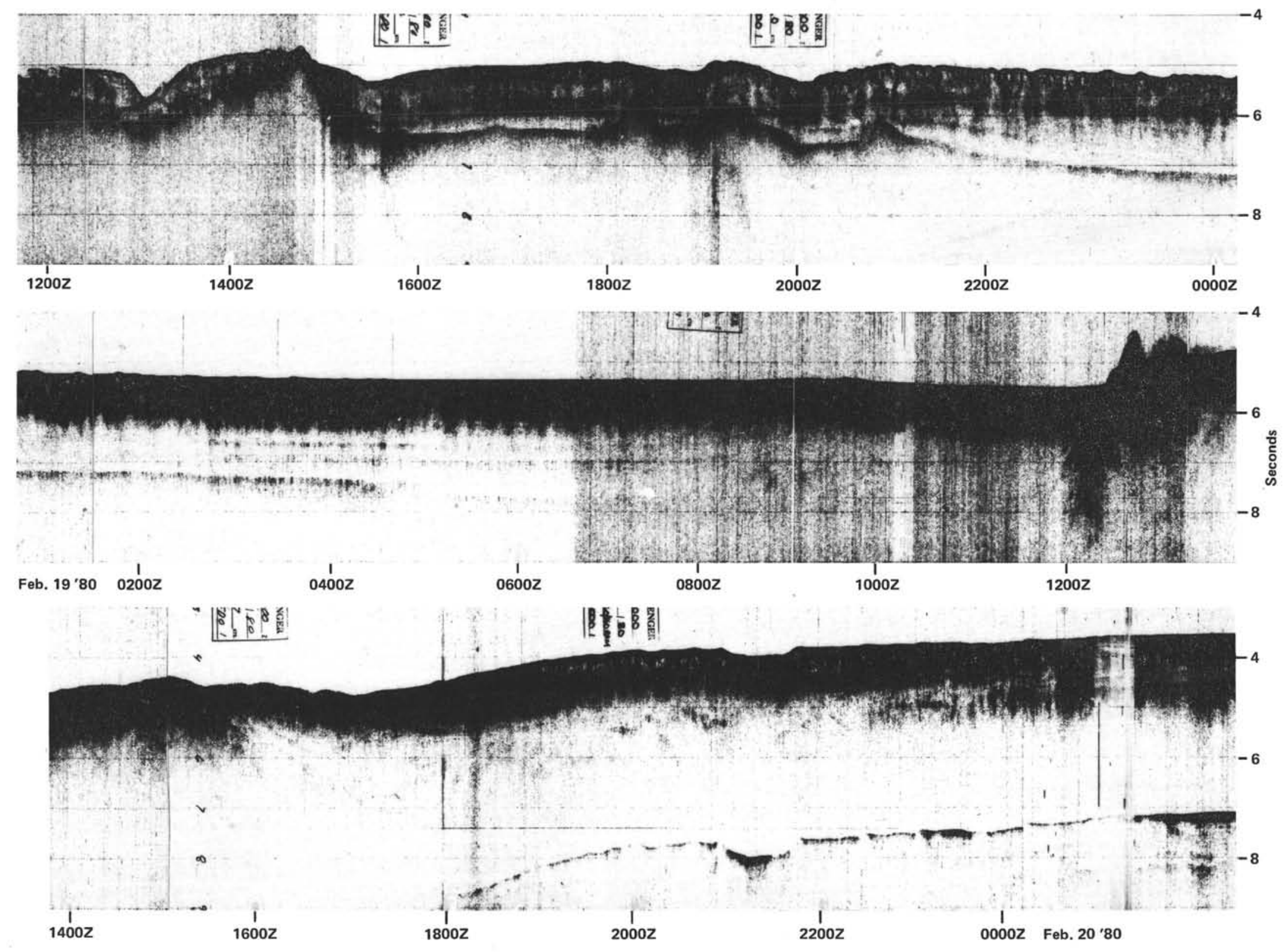

Figure 5. (Continued). 